\title{
Recent Progress and Approaches on Carbon-Free Energy from Water Splitting
}

Cite as

Nano-Micro Lett.

(2019) 11:103

Received: 2 October 2019

Accepted: 3 November 2019

Published online: 22 November 2019

(C) The Author(s) 2019

\author{
Aslam Hossain $^{1}$, K. Sakthipandi ${ }^{2}$, A. K. M. Atique Ullah ${ }^{3}$, Sanjay Roy ${ }^{4}$ \\ $\triangle$ K. Sakthipandi, sakthipandi@gmail.com \\ 1 Department of Physical and Inorganic Chemistry, Institute of Natural Science and Mathematics, Ural \\ Federal University, Yekaterinburg, Russia \\ 2 Department of Physics, Sethu Institute of Technology, Kariapatti, Tamil Nadu 626 115, India \\ 3 Nanoscience and Technology Research Laboratory, Atomic Energy Centre, Bangladesh Atomic Energy \\ Commission, Dhaka 1000, Bangladesh \\ 4 Department of Chemistry, Shibpur Dinobundhoo Institution (College), Howrah, West Bengal 711102, India
}

\section{HIGHLIGHTS}

- Different approaches for efficient carbon-free energy from water splitting are summarized.

- Step-wise evolution of water splitting research is highlighted with current progress.

- It describes the open challenges of charge transport properties and future research direction.

\begin{abstract}
Sunlight is the most abundant renewable energy resource, providing the earth with enough power that is capable of taking care of all of humanity's desires - a hundred times over. However, as it is at times diffuse and intermittent, it raises issues concerning how best to reap this energy and store it for times when the Sun is not shining. With increasing population in the world and modern economic development, there will be an additional increase in energy demand. Devices that use daylight to separate water into individual chemical elements may well be the answer to this issue, as water splitting produces an ideal fuel. If such devices that generate fuel were to become widely adopted, they must be low in cost, both for supplying and operation. Therefore, it is essential to research for cheap technologies for water ripping. This review summarizes the progress made toward such development, the open challenges existing, and the approaches undertaken to generate carbon-free energy through water splitting.
\end{abstract}

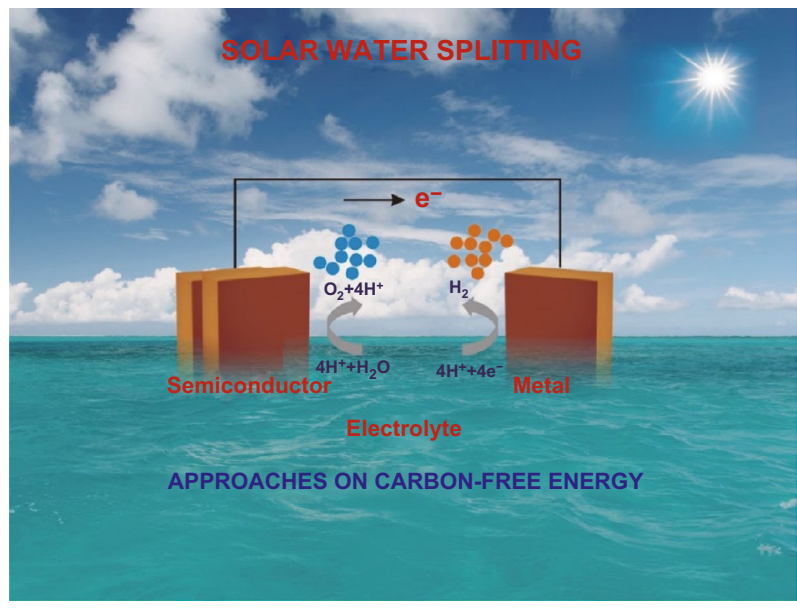

KEYWORDS Water splitting; Renewable energy sources; Hydrogen generation; Photocatalysis; Nanostructure

\section{Introduction}

The world's power supply relies predominantly on nonrenewable energy resources such as oil, coal, and fossil fuel (natural gas). These geological resources have accumulated over countless millions of years through photosynthetic activity. Therefore, such fuel is representative of 'solar energy' [1-3]. However, steep rises in energy consumption over the last century have resulted in an inevitable shortage of those valuable resources. This impact is already being seen to a lesser extent with the economic, social, and political changes. Increase in human 
population and economic process, especially in fast-developing countries, can result in an additional increase in energy demand. Furthermore, the burning of carbon-rich fuels has redoubled the carbon dioxide concentration in the atmosphere. This increase is capable of influencing evolution and climate changes, with projected adverse effects for our planet and the human society [4]. Therefore, all countries need to challenge themselves to identify and develop various alternative energy sources [5, 6].

Solar power is by and far the most important source of renewable energy $\left(\sim 1.2 \times 10^{14} \mathrm{~kJ}\right.$ is received by the earth's surface every second) [7].Therefore, it is only natural that there is significant interest to trap this irradiation and chemically apply it to generate energy [8]. Consequently, in recent years, there has been an outburst of research to target the direct solar energy for the production of fuel devices. Such direct solar-to-fuel devices may be considered to be 'artificial photosynthesizers,' as they capture the daylight energy, use it to react with chemical bonds, and produce a final product that is referred to as 'solar fuel' (in this case, $\mathrm{H}_{2}$ ) [9].

Currently, several review articles have reported on water splitting (WS) specifically. Numerous recent reports have dealt with WS research on the surface engineering of nanomaterials [10], plasmon-enhanced visible light-driven WS [11], surface and interface engineering for photoelectrochemical water oxidation [12], mechanistic understanding of the plasmonic enhancement for solar WS [13], and defects engineering in photocatalytic WS materials [14]. Therefore, this review aims to highlight the current progress, the approaches on carbon-free energy sources, and step-wise theoretical and experimental research on WS.

This review intends to summarize the recent evolution in the theoretical approaches for WS and the various costeffective strategies developed. This is dealt in the context of the solar energy's potential use in photoelectrochemical solar-to- $\mathrm{H}_{2}$ devices. We aim to reinforce the demand for whole-system approaches, especially among those who are already dealing with electrocatalytic WS. However, this review is especially meant to educate and encourage those who are new to this field and challenge them to contribute to this fascinating, ever-changing area of research. Information regarding in-depth strategies applied for electrocatalytic chemical element evolution $\left(\mathrm{H}_{2}\right.$ evolution) [15] and gas evolution [16] (oxygen evolution) is dealt with in this review. We focus totally on the progression made by the various elementary studies in this field, in addition to short highlighters regarding the various recently developed approaches to get carbon-free energy by WS.

\section{Revolution of Water Splitting Research}

Since the primary demonstrations of photoelectrochemical WS in the 1970s [17], several resources and analyses have been dedicated to develop affordable elements for generating solar fuel systems. Previous reviews surveyed the information regarding the physical and thermodynamic principles involved in $\mathrm{H}_{2}$ and $\mathrm{O}_{2}$ evolution reactions, the performance of assorted semiconductors, the configurations of photoelectrochemical cells, the properties of catalysts, and the influence of assorted structural influences on the efficiency of the method [18]. They additionally summarized the values obtained for the energy conversion efficiency or the alleged solar-to-atomic number 1 efficiency, which were obtained for WS cells of various configurations. The values varied between 0.01 and $18 \%$, that is, by an element of concerning 2000, for photoelectrochemical cells while not surface catalysts and people with catalysts and buried electrical phenomenon junctions (photovoltaic).

To technically understand the process, direct solar-tochemical energy conversion in photoelectrochemical cells is described, with emphasis on economical and cost-effective techniques for $\mathrm{H}_{2}$ production. The techniques were compared with the method that involved electrolysis of water for photovoltaic-generated electricity. It also deals with integrating light-weight energy usage and WS into a single device [19]. This goal, however, poses serious materialrelated challenges: Semiconductor photoelectrodes ought to expeditiously harvest solar irradiation and drive water oxidation or reduction reactions with a sufficient rate of current densities (10-15 $\left.\mathrm{mA} \mathrm{cm}^{-2}\right)$ in liquid solutions underneath one Sun illumination while not degrading for an appropriately extended period of time, that is, over $2000 \mathrm{~h}$ consistent with benchmarks set by the Department of Energy, the USA [20]. All these aforementioned aspects cannot be met by a single material, and therefore, formation of assorted heterostructures [19] is not possible. Bicycle-built-for-two (tandem) devices [21] have been developed for photocorrosion protection of semiconductors [22]; however, they have not proven to be efficient in its usage during 2010-2016, as is seen by the documented literature. 
The highest solar-to- $\mathrm{H}_{2}$ efficiencies that exceed $10 \%$ have been until now generated using costly and unstable semiconductors that belong to the III to V groups [23]. Therefore, the central focus of a research in this field is to discover economically viable, efficient, and stable material compositions for photoelectrochemical WS, especially among elements abundant on the earth. Most Si photovoltaic cells are being deployed to generate solar $\mathrm{H}_{2}$, as this technology is not only well developed already but is also additionally significant as the cost of the crystalline chemical element in the star cells has reduced over seven times within the past few years [24]. Despite the fact that there has been vital progress in understanding the physical challenges involved in the fabrication of sensible solar fuel generators, the analysis of the technoeconomical implications for their deployment has been limited. These value implications are extraordinarily necessary for realizing business implementations of solar fuel technologies.

One of the major challenges for controlling the price of solar- $\mathrm{H}_{2}$ systems is related to the shortage in reference demonstrators for base calculations. Despite this challenge, many studies in the literature have provided insights in the value and energy needs for solar- $\mathrm{H}_{2}$ production using designs believed to be promising candidates [25]. In addition, a comprehensive sensitivity analysis on system parameters (both physical and economic factors) is under progress to elucidate their overall impact on the price of $\mathrm{H}_{2}$ created. This approach allows for a good comparison among the various solar- $\mathrm{H}_{2}$ generation systems based on cost-effectiveness and benefit $\left(\$ / \mathrm{kg}\right.$ of $\left.\mathrm{H}_{2}\right)$. Rodriguez et al. [26] primarily outlined the price of $\mathrm{H}_{2}$ on the basis of the light-absorbing element (up to $97 \%$ of the cost), stating that the material choice for electrolysis has, to a large extent, minor effects. The findings discussed here will facilitate direct analysis and help develop deployable solar- $\mathrm{H}_{2}$ generators that have competitive value in relation to energy sources that may be efficient in terms of cost. Figure 1 shows the price (left graph) of $\mathrm{H}_{2}$ for all attainable combinations of catalysts with $F$ (quantitative relation between electrolysis area and photovoltaic area) $=1$ (i.e., corresponding to the magnitudes of solar fuel generators based on photoelectrodes) and (right graph) an optimized value for $F$.

Reece et al. [27] developed solar WS cells consisting of triple junction amorphous $\mathrm{Si}$ electric cell interfaced with cobalt borate and $\mathrm{NiMoZn}$ as $\mathrm{O}_{2}$ and $\mathrm{H}_{2}$ evolution catalysts,

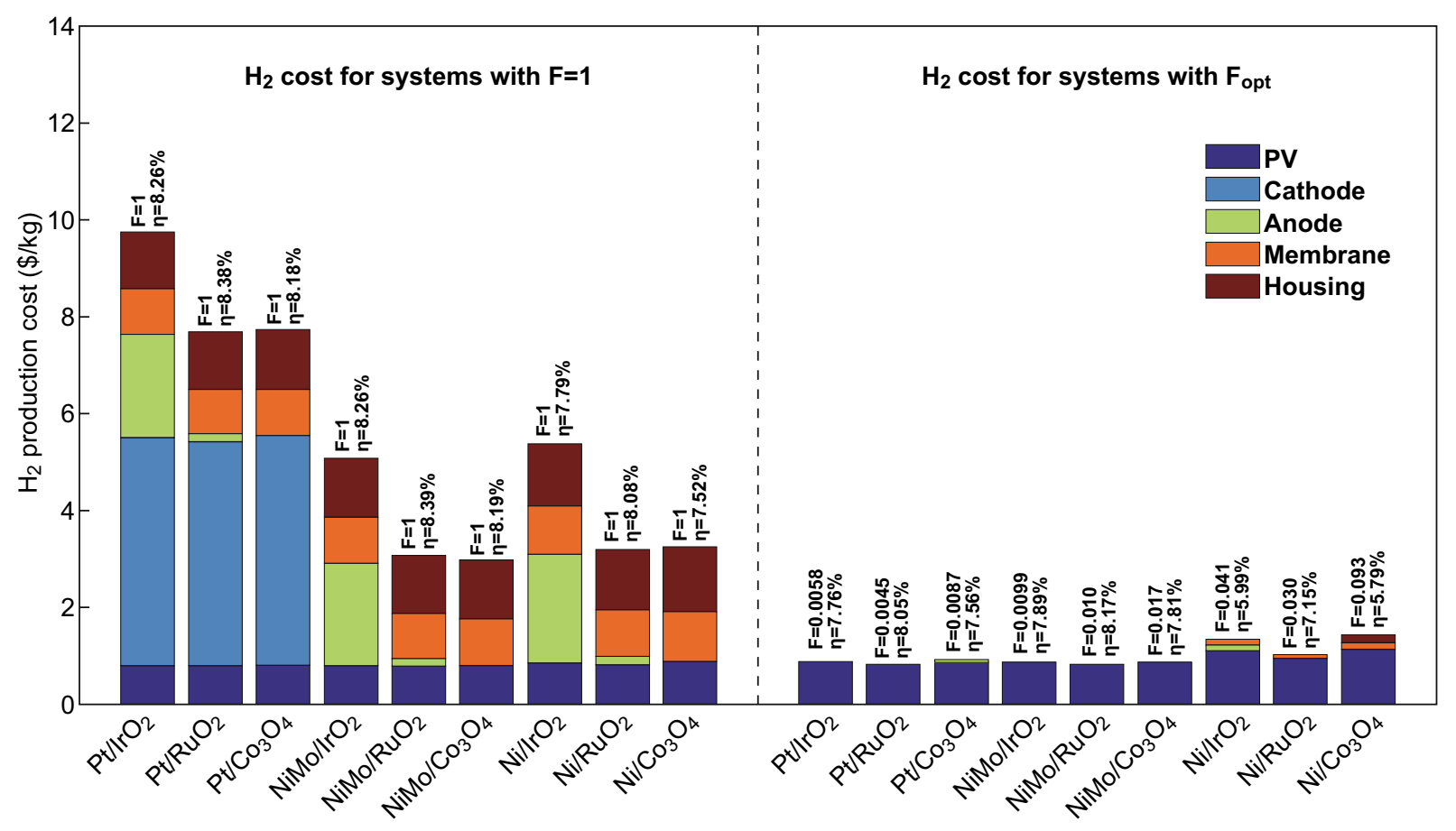

Fig. 1 Cost comparison and evaluation of solar- $\mathrm{H}_{2}$ generators that integrate different catalytic components. Reproduced from Ref. [26] with permission from the Centre National de la Recherche Scientifique (CNRS) and The Royal Society of Chemistry 
respectively. The best-obtained solar-to- $\mathrm{H}_{2}$ efficiency rate was $4.7 \%$ underneath one Sun illumination; however, a stable operation could be conducted on the device for just $10 \mathrm{~h}$. Chen et al. [22] successfully stabilized chemical element photoanode by atomic-level layer deposition/coating of 2 nm thick using $\mathrm{TiO}_{2}$ lined with 3 -nm-thick metallic element film; this was suitable for oxygen evolution by catalysis reactions. Stable operation of the anode was ascertained for a minimum of $24 \mathrm{~h}$. Similarly, atomic layer depositiongrown Al-doped $\mathrm{ZnO}(20 \mathrm{~nm})$ and $\mathrm{TiO}_{2}(20 \mathrm{~nm})$ protective layers changed with $\mathrm{Pt}$ nanoparticles have been shown to effectively stabilize $\mathrm{Cu}_{2} \mathrm{O}$ photocathode [28] for $\mathrm{H}_{2}$ production, which retained $62 \%$ of the initial photocurrent value after $10 \mathrm{~h}$ stability check. Kenney et al. [29] set a record of 80-h-long direct water oxidation using n-type Si photoanodes passivized with a 2-nm-thick nickel film, which acted additionally as an oxygen evolution catalyst.

Considering the aforementioned research, the apparent 'brute-force' or photovoltaic reaction along with the electrolysis phenomenon is recently being reconsidered [30]. The benefit of this technical scheme is that both processes, that is, the photovoltaic and electrochemical energy conversions, can be optimized independently. Moreover, the issues connected with blocking of the photosensitive surface with $\mathrm{H}_{2}$ or $\mathrm{O}_{2}$ evolution reaction catalyst particles and photocorrosion of semiconductors are mechanically avoided. Recently, solar-to- $\mathrm{H}_{2}$ efficiency exceeding $10 \%$ was achieved with a noble metal, with crystalline silicon photovoltaics module and low-value $\mathrm{H}_{2}$ and $\mathrm{O}_{2}$ evolution reaction catalysts [25]. About $12.3 \%$ solar-to- $\mathrm{H}_{2}$ efficiency using inexpensive perovskite photovoltaics and earth-rich catalysts has been reported recently [30]. Although the results are promising, the instability of perovskite electric cell limits the time period of WS device. For efficient applications, the expected time period for a solar-powered device that is run by solar cells should be 25 years. Thus, it is evident that for construction of an economical solar WS system, a trade-off between potency, cost-value, and longevity should be achieved.

\section{Different Approach for Water Splitting Research}

The current status of energy demand drastic conflict with the limited fossil fuel supply in nature which is inspiring to research for the development of sustainable energy sources.
Solar energy is one of the flexible and universal promising candidates which can be utilized by photovoltaic and photothermal approaches. So, the conversion of solar energy to chemical energy is very important to solve the future energy problem. The several theoretical and experimental approaches for photoelectrochemical WS are important in modern science which is discussed here.

\subsection{Plasmonic Solar Approach for WS}

Plasmonics is a promising functional field of science and technology, which exploits the unique optical properties of nanometallic structures to manipulate light and its pathways at nanometer length scales. Nanometallic objects develop their properties from the ability to maintain collective electron excitation, known as surface plasmons. Currently, plasmonics research has enabled new fundamental science and instrumentation technologies. Plasmonics may soon become a widespread technology, offering rare optical capabilities and the opportunity to achieve unprecedented intensity levels of synergy between optical and electronic functions. Although resistive heat loss in metals can severely limit the enactment of devices that rely critically on long-range propagation of waves on surface plasmon (surface plasmon polaritons), despite the presence of losses, recently, numerous useful functionalities have been realized. The most prominent ones are related to practice structures for excessive light concentration, such as lenses, resonators, and plasmonic antennas; all of these are excellent examples of this technology [31-33].

Plasmon enhancement is an exciting track route to control the drift of electromagnetic energy in photocatalytic and photoelectrochemical WS devices. Energy transfer during plasmon resonance enables precise spatial control over photon absorption in a semiconductor. This approach is particularly beneficial in materials where photocurrent is limited by a small minority carrier transport distance, although the full range of the advantages of plasmon resonance transfer energy has yet to be explored. Many emerging semiconductors, which are both of scientific and economic interest, such as hematite, are excellent candidates for studying the plasmonic effect because these similar or same semiconductors often have high defect densities that promote recombination. 
Plasma resonance energy transfer can provide advantages for generating less expensive or rare semiconductors by reducing the amount of semiconductors required for photoabsorption. Through plasmonics, semiconductors may become by and large capable of absorbing the same quantity of light using third-order magnitude lower semiconductors [34], thereby effectively focusing light and increasing photovoltage and efficiency. It may also be possible to fabricate a device with a smaller semiconductor-electrolyte interfacial region than the projected area of the substrate, leading to a dramatic upturn in photovoltage.

Although metals have high inherent chemical activity and the ability to selectively activate many chemical transformational changes, it has been assumed that the percentage of photocatalytic reactions on metals at photon intensities such as that of the Sun is characterized by energetic charge carrier formation and short lifetimes. However, these are very few due to low capacity [35]. It was recently shown that unlike metal structures, plasmonic photoexcited nanostructures show relatively high photocatalytic activity when exposed to photons of Sun-like intensity [36]. So far, observations on plasmonic nanostructures of direct photocatalysis have been restricted to partial exothermic oxidation only, selective reduction, and decomposition organic chemical reactions on excited plasmonic $\mathrm{Au}$ and Ag nanostructures.

(a)

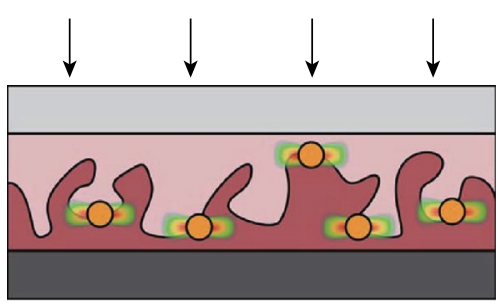

(c)

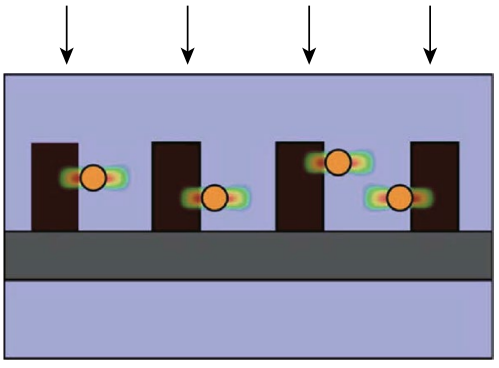

Organic solar cells (Fig. 2a) typically exploit metallic nanoparticles of small particles to lead to heterojunction where separation of charge occurs [37], although other geometries have also been explored [38]. This allows light to be localized at the interface between two phases. Inorganic solar cells (Fig. 2b), such as those established on silicon $p-n$ junctions, have generally exploited plasmonic nanoparticles positioned at some distance from the $p-n$ junctions. In most cases, the primary mode of operation is by light scattering [39], although some contribution of near-field effects is possible [40]. In WS devices, the electric field that separates electrons and holes is located at the semiconductor-water interface. Unlike most conventional inorganic solar cells, which have a buried space charge layer, metal nanoparticles can be placed at the semiconductor-water interface, allowing near-field energy transfer from semiconductor to metal in a manner consistent with organic solar cells. Additionally, scattering effects may additionally be applied in WS devices. Although there has not yet been any demonstration of plasmon-enhanced WS using plasmon-light scattering, planar geometries will likely be chosen (Fig. 2d), as they have been under study for solar cells (Fig. 2c) that exploit the light trap [41, 42].

There are several reports available regarding the usage of plasmonic photocatalysts for WS. In 2011, considerable attention was given to the production of hydrogen by WS using a plasmonic photocatalyst under visible light

(b)

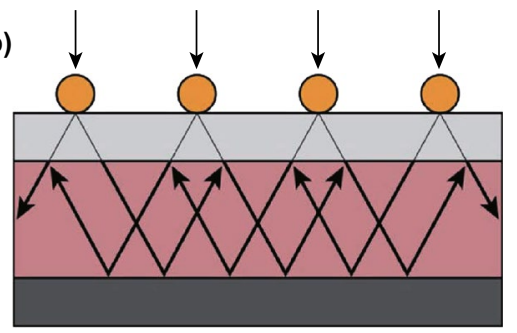

(d)

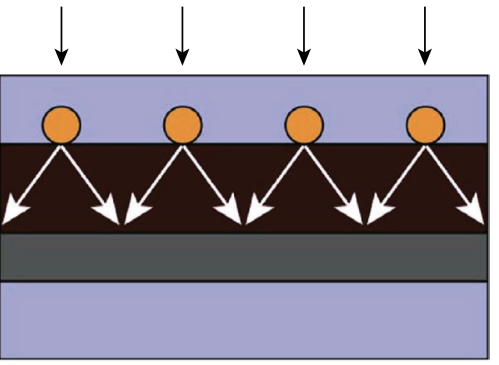

Fig. 2 Device proposal/design for solar cells $(\mathbf{a}, \mathbf{b})$ and analogous designs for photoelectrochemical cells (c, d). Reprinted from Ref. [42] with permission from the Centre National de la Recherche Scientifique (CNRS) and The Royal Society of Chemistry 
illumination [43]. Thereafter, Ag film-based $\mathrm{ZnO}$-coated nanorods of varying thickness on a polyethylene terephthalate flexible substrate photoanode were used for photoelectrochemical WS [44]. The fabricated photoanode of $\mathrm{Ag}$ nanoparticles in the (NPs)/ $/ \mathrm{WO}_{3}$ film showed plateau photocurrent, which was about 1.6 times that for pristine $\mathrm{WO}_{3}$ photoanode without Ag NPs [45]. Further, $\mathrm{Ag} @ \mathrm{SiO}_{2} @$ $\mathrm{TiO}_{2}$ core-shell photocatalysts with different thicknesses of $\mathrm{SiO}_{2}$ interlayer were fabricated, and significant photocatalytic activity was obtained by Zhang et al. [46] under visible light. Ingram et al. [47] reported WS on composite plasmonic-metal/semiconductor photoelectrodes using Au-NPs or Ag NPs onto nitrogen-doped $\mathrm{TiO}_{2}\left(\mathrm{~N}-\mathrm{TiO}_{2}\right)$. Although the reported conductivity and electronic structure of $\mathrm{Au}$ and $\mathrm{Ag}$ are similar, Au-surface plasmon resonance shifted relative to that of Ag and did not overlap expressively with the absorption spectrum of $\mathrm{N}-T i O_{2}$, as shown in Fig. 3. The overall WS suggested due to stoichiometric amounts of $\mathrm{H}_{2}$ and $\mathrm{O}_{2}$
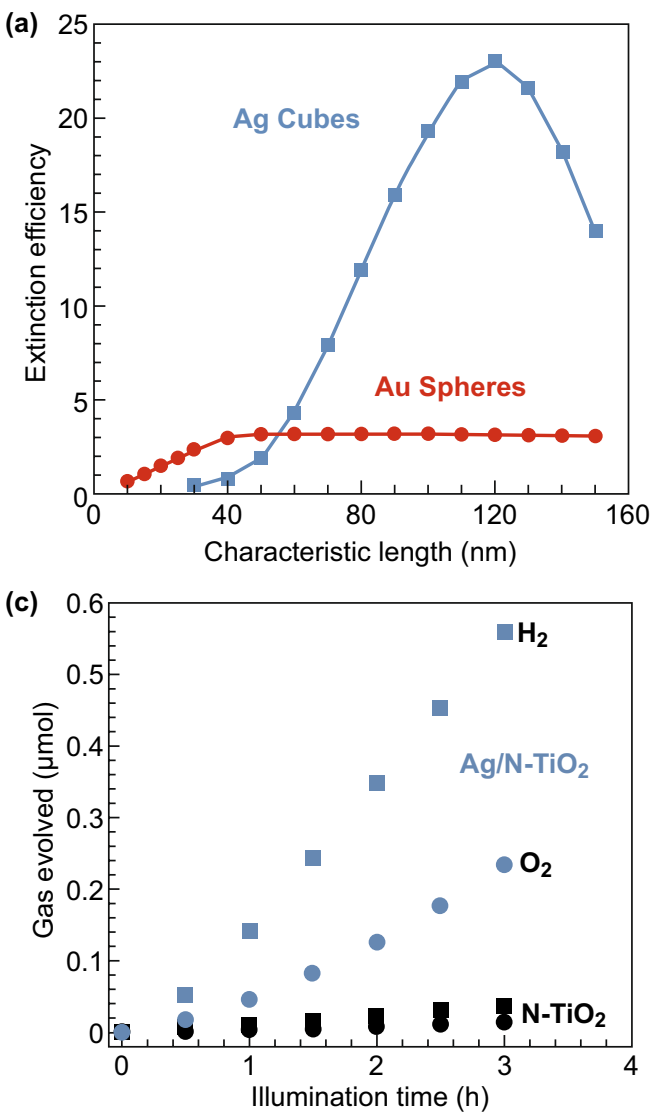

was produced by photoelectrodes with a broadband visible source, as shown in Fig. 3c. The effect of Au-NPs is small on the photocurrent, but the addition of plasmonic Ag-NPs to $\mathrm{N}-\mathrm{TiO}_{2}$ by ten times increases the visible light photocurrent as shown in Fig. 3d.

\subsection{Physics and Surface Chemistry for Optimization of WS}

The semiconductor photoelectrodes involve in complex chemical, physical, and electrical processes during the process of solar WS reaction, thereby operating the photogenerated electron-hole pairs for redox reactions [48]. Recent WS research has established three steps for the process: charge carrier generation in the semiconductor photoelectrodes, migration of charge carriers from the bulk to the surface, and redox reactions on the surface reaction sites. The activities of the photoelectrodes can be determined
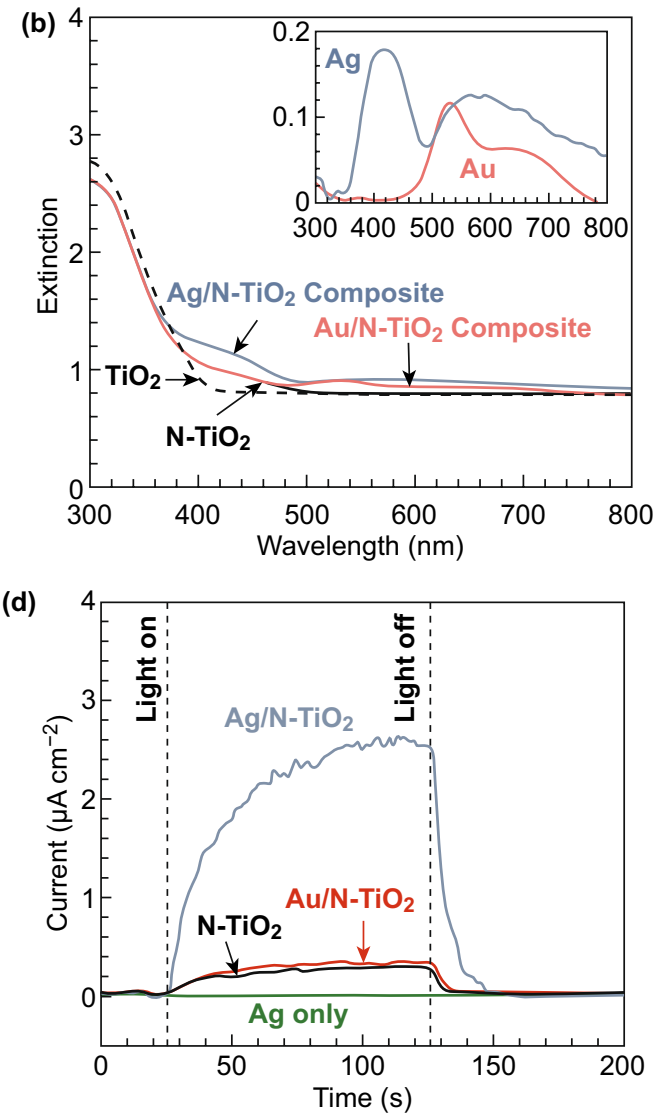

Fig. 3 a Extinction efficiencies for Ag cubes and Au spheres as functions of particle size. b UV-Vis extinction spectra of samples. $\mathbf{c} \mathrm{H}_{2}$ and $\mathrm{O}_{2}$ production upon visible illumination of photocatalysts. d Photocurrent responses upon illumination with a broadband visible light source. Reprinted with permission from Ref. [47], Copyright (C) 2011, American Chemical Society 
by the efficiency of these steps. Subbaraman et al. [49] enhanced the hydrogen evolution activity in WS by tailoring $\mathrm{Li}^{+}-\mathrm{Ni}(\mathrm{OH})_{2}-\mathrm{Pt}$ interfaces. They found that controlled arrangement of $\mathrm{Ni}(\mathrm{OH})_{2}$ nanoclusters on the surface of platinum electrode will enhance the activity of catalyzing the hydrogen evolution reaction by eight times compared to metal oxide catalysts. Recently, Luo et al. [50] reported surface chemistry engineering toward universal-pH catalysts for hydrogen evolution. On the basis of these studies, an efficient catalyst for hydrogen evolution reaction at high current density over a range of $\mathrm{pH}$ values was manufactured. Microspheres are composed of radially aligned $\mathrm{MoS}_{2}$ nanosheets with $\mathrm{Mo}_{2} \mathrm{C}$ nanoparticles at their edges (Fig. 4a).

The surface engineering approaches have been extensively used for developing the photoelectrochemical performance of nanostructured photoelectrodes. One of the most important methods to passivate the surface states of semiconductor photoelectrodes is atomic layer deposition (ALD). This technique is used to produce thin films with exact controlled thickness and proper growth over complex nanostructures [51]. This ideal modern method controls the surface states without intensely changing the surface properties or eliminating the injection of charge carriers [52]. Le Formal et al. [53] claimed that an ultrathin coating of ALD-grown $\mathrm{Al}_{2} \mathrm{O}_{3}$ can decrease the overpotential of $\alpha-\mathrm{Fe}_{2} \mathrm{O}_{3}$ photoanode and, subsequently, enhance the photocurrent density (Fig. 4b). Zhang et al. [54] showed that the addition of a sacrificing agent such as $\mathrm{H}_{2} \mathrm{O}_{2}$ into the electrolyte enhances the photocurrent of the $\mathrm{Ta}_{3} \mathrm{~N}_{5}$ thin film photoanode (Fig. 4b).

(a)

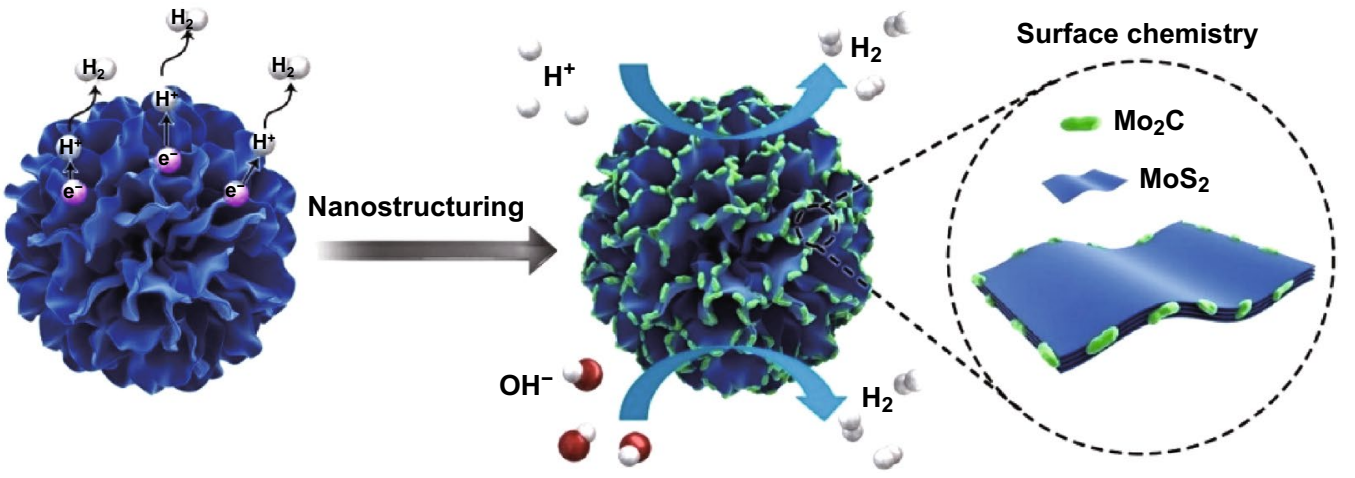

(b)

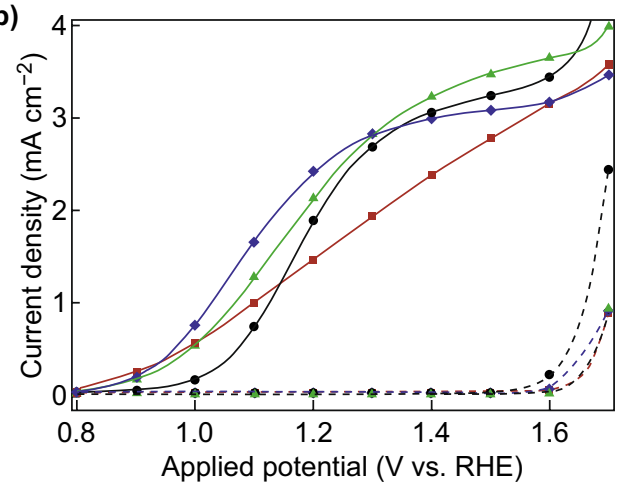

(c)

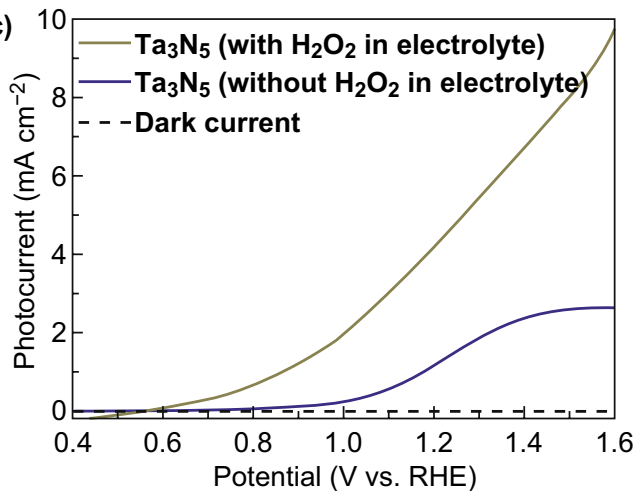

Fig. 4 a Schematic represent of the $\mathrm{MoS}_{2} / \mathrm{Mo}_{2} \mathrm{C}$; reprinted with permission from Ref. [50], Copyright $\odot$ 2019, Springer Nature. b Current densities of photoanodes in the dark (broken lines) and under simulated solar are shown as a function of the applied potential, $V$, with respect to the RHE. An atmospheric pressure chemical vapor deposition sample covered with one ALD cycle of $\mathrm{Al}_{2} \mathrm{O}_{3}$ has been measured after deposition (red squares), after annealing for $20 \mathrm{~min}$ at $300{ }^{\circ} \mathrm{C}$ (green triangles) and after annealing for $20 \mathrm{~min}$ at $400{ }^{\circ} \mathrm{C}$ (blue diamonds), sample before ALD (black circles). Reprinted from Ref. [53] with permission from The Royal Society of Chemistry, $\mathbf{c} J-V$ curves of Ta $\mathrm{N}_{5}$ thin film photoanode in the electrolyte with and without $\mathrm{H}_{2} \mathrm{O}_{2}$ sacrificial agent. Reprinted from Ref. [54] with permission from the Centre National de la Recherche Scientifique (CNRS) and The Royal Society of Chemistry 


\subsection{Electrode-Electrolyte Interface Engineering Approach for WS}

Water oxidation and reduction take place at the electrode-electrolyte interfaces; therefore, extremely large surface area of photoelectrodes is important for enhancing its efficiency in WS. The advanced surface engineering that involves deposition of mono- or multilayer modifiers at the semiconductor-electrolyte interface has a crucial role in improving photoelectrochemical performances. After surface modification, several new interfaces appear, such as the semiconductor-modifier interface, the modifier-electrolyte interface, and additional interfaces between adjacent layers of modifiers in the case of multilayer modification. Proper interface engineering of the active semiconductor electrode-electrolyte contact is the main challenge of a water splitting device. The crucial part is to form semiconductor-passivation layer co-catalyst-electrolyte interfaces, which would be capable of achieving the desired reactions without potential and current loss. Since the early stage of photoelectrochemical WS development, the solid-liquid interface has attracted much attention. Currently, several reports are available regarding the tuning of the efficiency of solar WS using electrode-electrolyte interface engineering. Zhang et al. [55] reported interface engineering of monolayer $\mathrm{MoS}_{2} / \mathrm{GaN}$ hybrid heterostructure for photocatalytic WS application. Kang et al. [56] summarized the details regarding the interface engineering of modulation charge carrier nature in $\mathrm{ZnO}$ photoelectrochemical WS.

\subsection{Defect Engineering for WS}

The concept of defect engineering is correlated with the reconstruction of a surface to reduce the density of surface defects. The approach of defect engineering is to tune the electronic structure to improve photoelectrochemical performance by the formation of a surface disorder or intrinsic defects. Recently, a study has confirmed that defect engineering is an effective approach to modulate the electronic band structure, charge carrier transfer, and surface-active sites construction of photocatalysts [57]. The defect in semiconductors is of four types depending on the dimensions of the crystal lattice; they are 0D point defects, 1D line defects, 2D planar defects, and 3D volume defects, respectively [58]. 0D point defect controls the nonstoichiometric compositions that are related to the conductivity of most semiconductor materials.

Several methods have been introduced to deal with surface defects in semiconductors: hydrogen gas annealing [59], thermal annealing [60], flame annealing [61], partial oxidation [62], aluminothermic reduction [63], ultrasonication [64], chemical reduction [65], and electrochemical treatment [66]. In 2011, the concept of creating surface disorder was first demonstrated on $\mathrm{TiO}_{2}$ photoelectrode for photoelectrochemical WS [59]. Further, the research claimed that the control of intrinsic surface defects (oxygen vacancies) can expressively lead to the growth of photoelectrochemical performance of metal oxide photoelectrodes [67]. Cho et al. [68] claimed surface oxygen vacancies on different metal oxides by introducing a general flame reduction method. Figure 5 represents the

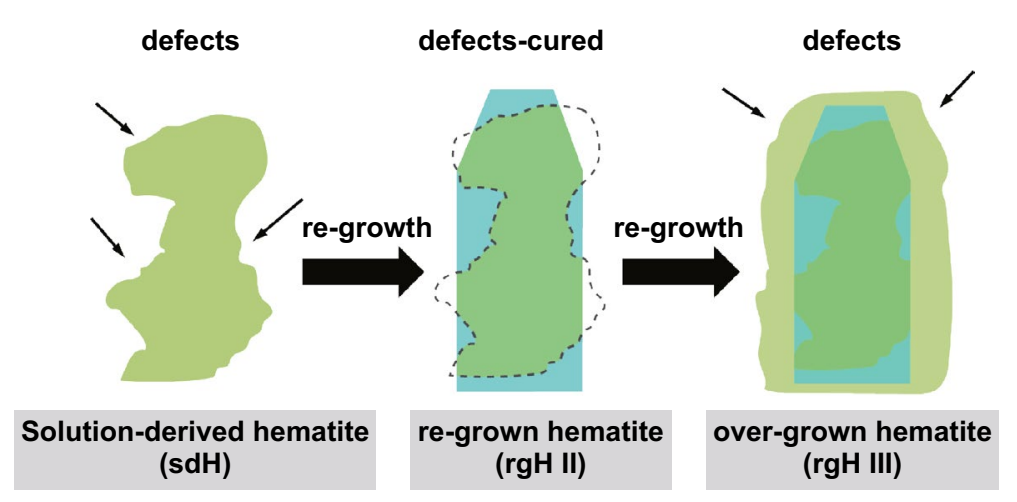

Fig. 5 Defect engineering using re-growth scheme of hematite. Reprinted with permission from Ref. [69], Copyright @ 2015, Springer Nature 
solution-based re-growth procedure to study the hypothesis, wherein pre-formed hematite is exposed to acidic solutions under which condition dissolution ( of $\mathrm{Fe}_{2} \mathrm{O}_{3}$ ) and deposition (of $\mathrm{FeOOH}$ ) occur concurrently [69].

\subsection{Biological Approach for WS}

Artificial photosynthesis systems store solar energy and reduce $\mathrm{CO}_{2}$ chemically. Photosynthetic reactions are mainly determined by three stages of reaction processes: the photosynthetic process; charge generation and separation processes; and catalytic chemical reaction processes. The overall efficiency depends on the kinetics of these processes and the balance of thermodynamics. In recent decades, in-depth studies/experiments have focused on further investigation of the mechanisms involved in natural photosynthesis. In particular, the structure of the $\mathrm{O}_{2}$-evolving site has been revealed in photosystem II by researchers recently [70], thus giving new inspiration for the design of artificial photosynthetic structures.
WS is seen as an environmentally friendly and one of the most exciting ways to produce renewable fuels with abundant resources using solar power and photocatalytic semiconductors. Since the discovery of this method, hundreds of diverse semiconductors have been developed and tested for half the reactions (either $\mathrm{H}_{2}$ or $\mathrm{O}_{2}$ production) that involve WS, but are expensive [17]. Cost-effectiveness is a crucial goal of the entire WS community. For industrial applications, a necessary, non-debatable fact is that the methods employed must be robust, inexpensive, and efficient. Developing a photocatalyst that meets these requirements for WS remains a serious challenge within the field.

Nature splits $\mathrm{O}_{2}$ and $\mathrm{H}_{2}$ equivalent species into water by a dual excitation process, with the two half-reactions separated in PSII and PSI as shown in Fig. 6a [71]. Inspired by natural photosynthesis, Byrd proposed a conforming system composed of two inorganic semiconductor photocatalysts in 1979. This has been further developed based on recently developed photocatalysts [72, 73] on RH-doped $\mathrm{SrTiO}_{3}$ or $\mathrm{Ta}_{2}$ as $\mathrm{H}_{2}$, but there has been limited success. Tachibana
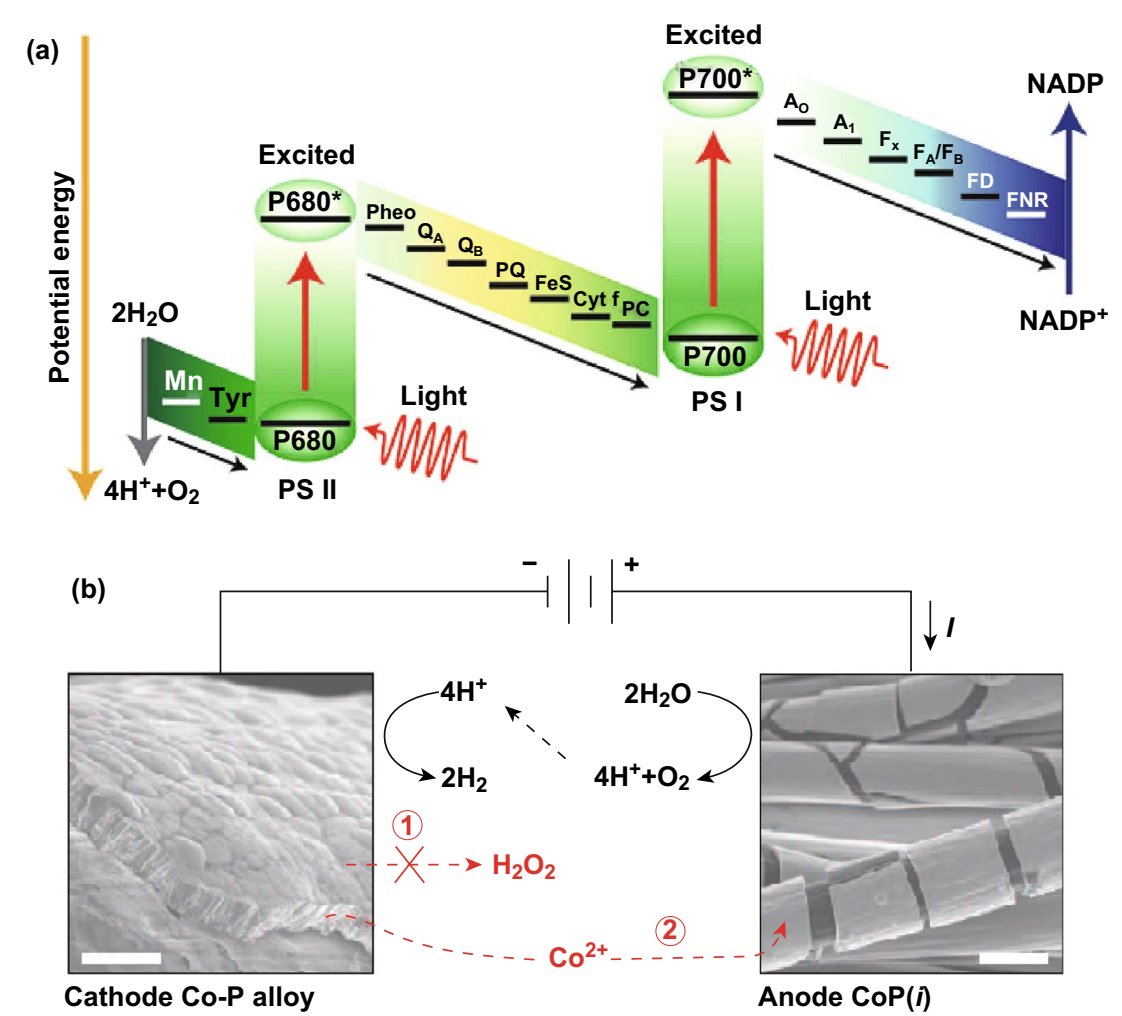

Fig. 6 Active water splitting catalyst pair with minimal biological toxicity. a Natural photosynthesis pathway and b reaction diagram and scanning electron microscopy images for Co-P alloy cathode and CoPi anode. Reprinted with permission from Ref. [9], Copyright @ 2012, Springer Nature and Ref. [75], Copyright (c) 2016, American Association for the Advancement of Science 
et al. [9] summarized some of the recent evolution in the development of artificial photosynthesis devices, with their subtypes for organic photosynthesis (biological photosynthesis), thereby focusing on the development of visible lightactivated heteronanostructures including techniques that require an underlying interfacial carrier dynamics.

Martin et al. [74] demonstrated that strong organic semiconductors such as graphitic carbon nitride can be integrated into natural photosynthesis in a nature-induced WS system corresponding to PSII and PSI. They developed two parallel systems for complete WS under visible light incorporating two different metal $\left(\mathrm{BiVO}_{4}\right.$ and $\left.\mathrm{WO}_{3}\right)$ oxides with graphitic carbon nitride. The facilitator is very important here because it significantly inhibits rapid repulsive recombination of charge, which is consistent with the electron chain transport between PSII and PSI. Given such benefits of a double excitation process, there are many researchers working on either two photocatalysts each favoring $\mathrm{H}_{2}$ or $\mathrm{O}_{2}$ production or a new mediator, which allows the charge between two photocatalysts to move efficiently.

More recently, Liu et al. [75] established a biological hybrid inorganic system that uses artificial leaf catalysts in blend with a bacterium Ralstonia eutropha to drive an artificial photosynthesis process for biomass and carbon fixation in liquid gels. In order to improve a biocompatible catalytic system that is not toxic to bacteria and is highly useful to WS, they introduced a reactive oxygen species (Fig. 6b, Route 1$)$, wherein cobalt-phosphorus (Co-P) resistant alloy cathode is used. This alloy conducts the $\mathrm{H}_{2}$ growth reaction, while the self-healing CoPi anode conducts the $\mathrm{O}_{2}$ growth reaction [76]. The electrode pair serves to maintain dissipated cobalt ions in low concentrations and to give a low applied voltage that splits water to generate $\mathrm{H}_{2}$ for Ralstonia eutropha, which results in $\mathrm{CO}_{2}$ in organic complex molecules at high-efficiency support shortages.

\subsection{Modeling Approach for WS}

Solar-to- $\mathrm{H}_{2}$ conversion efficiency, an important metric for evaluating the enactment of photoelectrochemical WS devices, is defined as a quantity of chemical energy produced as $\mathrm{H}_{2}$ is divided by input solar energy, with no externally applied bias. This is the most essential efficiency metric for comparing material and device performance and is useful in research for wide-scale benchmarking and comparison [77].
Modeling the theoretical device efficiency for photoelectrochemical WS is important as it can identify performance targets, guide the materials development process, and highlight aspects of device performance that need improvement. Researchers such as Weber and Dignam [78], Bolton et al. [79], and Rocheleau and Miller [80] expanded these initial analyses to photoelectrochemical WS to establish fundamental limits in that field.

The stability of the photoelectrodes against oxidation is regulated by the relative energy between their valence band maximum and intrinsic oxidation potential [81]. Such a complex interplay results in a multi-property optimization problem that is difficult to solve experimentally, especially due to challenges related to the structural characterization of interfaces. Theoretical models and computational studies therefore provide powerful tools to investigate photoelectronic interfacial properties and complement experiments. In particular, with recent advances in high-performance computing and sophisticated electronic structure theories and codes, the ability for routine modeling and simulation as a predictive tool is increasing rapidly, and now, it is a firstprinciples approach to electronic structure computation. The base approach may use molecular dynamics to accelerate material discovery for photoelectronic applications [82]. For example, it was demonstrated that first-principles calculations can be worked to scan combinations of 1000 elements throughout the periodic table to suggest new photoelectrode candidates [83].

In photoelectronic solar fuel conversion, an intermediate (medium) is converted into fuel with the benefit of sunlight and photoelectrochemical active materials. In the simplest way, it is the production of $\mathrm{H}_{2}$ by splitting water. Figure 7 illustrates the principle of a photoelectrochemical cell operation for WS in an alkaline environment. The three major disadvantages are related to the free energy losses in the photoexcited state. Electrons are excited from their ground energy state (i.e., valence band) to the excited state (conduction band) with the assistance of light illumination, which leaves a positively charged hole in the valence band. Consequently, the formation of an electron-hole pair is achieved.

In an n-type semiconductor, electrons travel to counter the electrode, on which they deplete water and form $\mathrm{H}_{2}$ gas $\left(4 \mathrm{H}_{2} \mathrm{O}+4 \mathrm{e}^{-} \rightarrow 4 \mathrm{OH}^{-}+2 \mathrm{H}_{2}\right)$. Holes move to the surface, at which they oxidize water to form oxygen gas $\left(4 \mathrm{OH}^{-}+4 \mathrm{~h}^{+} \rightarrow 2 \mathrm{H}_{2} \mathrm{O}+\mathrm{O}_{2}\right)$ [83]. Charge transport is restricted by the nature of semiconductor; electrode 


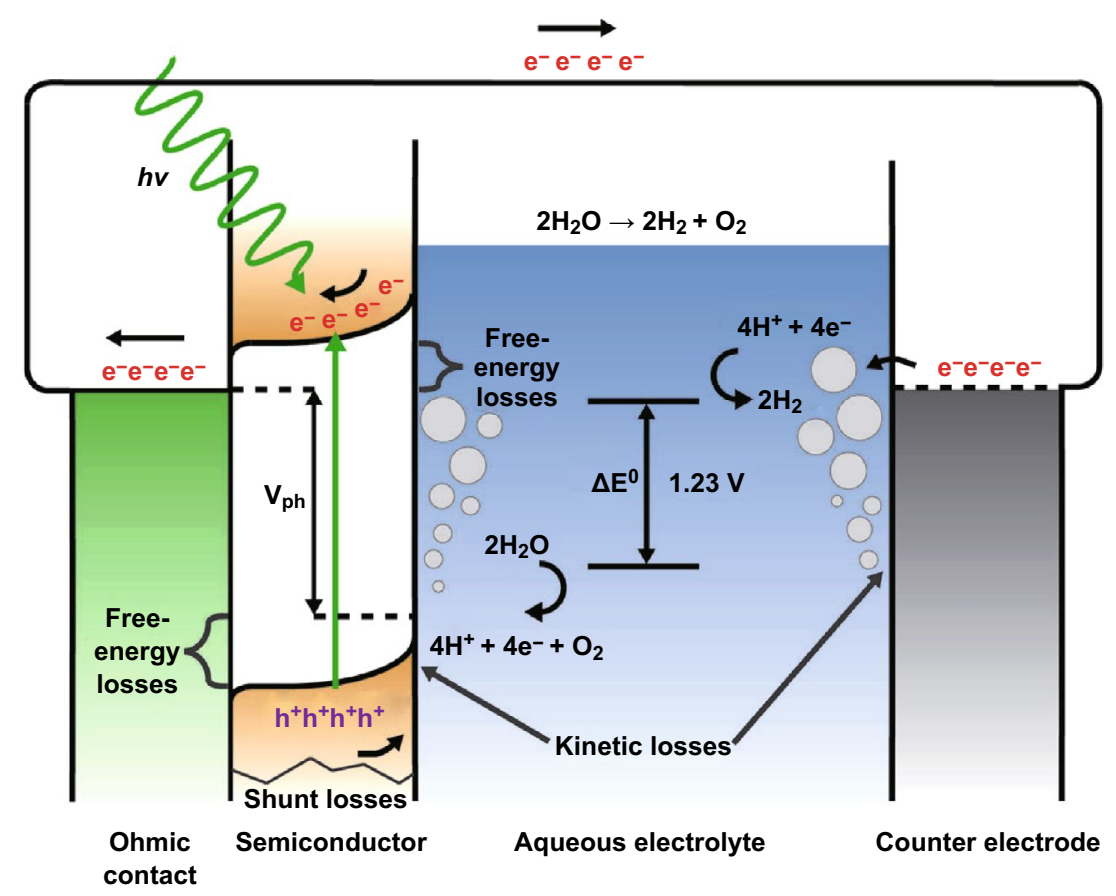

Fig. 7 Schematic representation of energy diagram of a photoelectrochemical cell for the photoelectrolysis of water with various losses. Reprinted with permission from Ref. [86], Copyright @ 2014 WILEY-VCH Verlag GmbH \& Co. KGaA, Weinheim

reactions are limited by the catalytic activity of the electrode material. Thus, both semiconductor physics and surface chemistry have to be carefully considered for optimization of photoelectrochemical systems [84, 85]. Photoelectrode materials suitable for efficient solar $\mathrm{H}_{2}$ generation must meet the following requirements:

1. Strong (visible) light absorption.

2. High chemical stability in the dark and under illumination.

3. Efficient charge transport in the semiconductor.

4. Appropriate band-edge positions to enable reduction/ oxidation of water.

5. Low overpotentials for the reduction/oxidation reactions.

6. Low cost.

Open challenges in first-principles predictions of processes relevant to solar-to-fuel conversion include simulations of interfaces not only with water but also with aqueous solutions under various $\mathrm{pH}$ conditions. Although some attempts have been made to inspect the interaction of solvated ions in contact with $\mathrm{TiO}_{2}$ surfaces, and ion effects on the electronic properties of the electrode [87, 88], these types of study are rather sparse due to the limitation in time and length scale accessible by first-principles approaches. Coupling first-principles molecular dynamics to advanced sampling methods [89] may help alleviate this problem in the near future. In addition, the use of techniques such as effective screening medium methods [90] may be suitable to study ion effects at photoelectrochemical interfaces during operation. Finally, electronic properties of ions at interfaces need to be better understood, and this is an area of active research [91] with some recent progress obtained by combining advanced hybrid functional with GW calculations [92].

Another open theoretical challenge is the description of charge transport properties, such as charge mobilities, which ultimately determine the device's efficiency. Evaluations of hole (p) and electron (e) mobilities as present in the literature, even if carried out from first principles, are still based on approximate theories that are often capable of yielding only correct orders of magnitude [93]. A unified first-principles approach that can describe the hopping (polaron) and band transport on the same footing is not yet available, and its development and application to realistic systems are a major challenge in predicting device efficiency for solar-to-fuel productions. In particular, although 
some recent progress was made on the study of the electron transfer rates at oxide interfaces [94], these calculations were based on transition-state theory and Fermi's golden rule, which usually focuses on a single process at a time.

\subsection{Thermodynamic Approach}

The solar thermochemical route additionally guarantees to be a suitable strategy for achieving this objective. The artificial chemical process and photovoltaic-powered electrolysis of water are promising approaches, though their implementation is somewhat restricted due to its low solarto-fuel conversion efficiency ( $\eta_{\text {solar-to-fuel }}$ ) of $<5 \%$ and $<15 \%$, respectively [95]. The alternative strategy is the solar thermochemical method that gives theoretically a high efficiency and allows large-scale production of $\mathrm{H}_{2}$ by using the entire solar spectrum [96]. One potential way to turn out $\mathrm{H}_{2}$ and carbon monoxide gas is to use thermochemical solar-driven cycles for WS. The obtained gases will be either used as a fuel directly or processed in a Fischer-Tropsch plant to get artificial hydrocarbons. Several thermochemical cycles have been investigated and evaluated within the past few years [97]. The cycle that has been subjected to the most analysis is the ballroom dancing cycle [98]:

Endothermic - metal oxide (MO) reduction:

$\mathrm{MO}_{x} \rightarrow \mathrm{MO}_{x-\delta}+0.5 \delta \mathrm{O}_{2}$

Splitting step:

$\mathrm{MO}_{x-\delta}+\mathrm{H}_{2} \mathrm{O} \rightarrow \mathrm{MO}_{x}+\delta \mathrm{H}_{2}$

The two-stage metal oxide process performed with the support of solar concentrators removes/eliminates the necessity to separate $\mathrm{H}_{2}$ and $\mathrm{O}_{2}$. The metal oxide reduces the metal or goes to a less valent metal oxide with the $\mathrm{O}_{2}(\mathrm{~g})$ release during the endothermic $\left(T_{\text {red }}\right)$ step, and in the next step, it re-oxidizes the reaction $\left(T_{\text {oxd }}\right)$ with release of a stoichiometric amount of $\mathrm{H}_{2}(\mathrm{~g})$, as shown in Fig. 8. In the twostep process, $\mathrm{T}_{\text {red }}>\mathrm{T}_{\text {oxd }}$ is the thermodynamic driving force to become viable as described by Eq. 3 in terms of the free energy $(\Delta G)$ change in the formation of $\mathrm{H}_{2} \mathrm{O}\left(\Delta G_{f, T_{\text {oxd }}}^{\mathrm{H}_{2} \mathrm{O}}\right)$ and the entropy of $\mathrm{O}_{2}\left(S_{T_{\text {red }}}^{\mathrm{O}_{2}}\right)$. Increasing $T_{\text {red }}$ temperature increases entropy $S_{T_{\text {red }}}^{\mathrm{O}_{2}}$, so the decrease in $\Delta T$ window can be permitted at higher $T_{\text {red }}$. Conversely, at lower $T_{\text {red }}, \Delta T$ has to be higher:

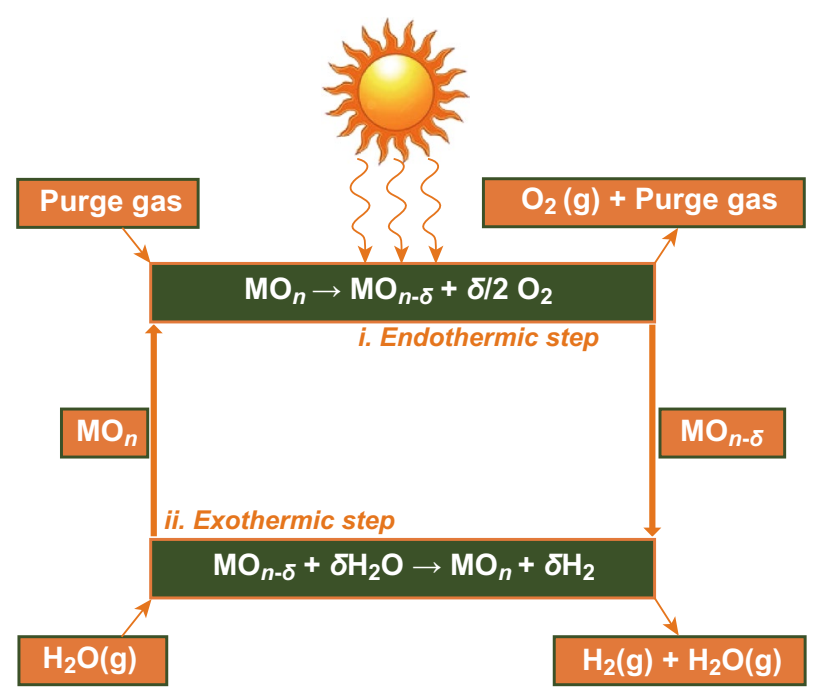

Fig. 8 Schematic representation of the two-step solar thermochemical splitting of $\mathrm{H}_{2} \mathrm{O}$ using nonstoichiometric metal oxide redox pairs and concentrated solar energy [100]

$\Delta T=T_{\text {red }}-T_{\text {oxd }}=-2 \Delta G_{f, T_{\text {oxd }}}^{\mathrm{H}_{2} \mathrm{O}} / S_{T_{\text {red }}}^{\mathrm{O}_{2}}$

Thermal reduction of the oxide and WS have been conducted at the same temperature $\left(T_{\text {red }}=T_{\text {oxd }}=T_{\text {iso }}\right)$ with a large pressure swing acting as the driving force in the gas composition between the reduction and oxidation processes $[99,100]$.

Using solar thermal channel, WS significantly depends on the accessibility of suitable solar reactors. The construction of a solar reactor capable of operating a variety of cycles, materials, and temperature systems has been discussed in some reviews in detail [101, 102]. The solar reactors have been applied to nonstoichiometric oxide-driven, nonvolatile, and twisted two-step cycles. The solar configuration consists of three fundamental parts: concentrator, receiver, and reactor. Ferrite has been widely investigated using solar radiation, and there have been some attempts to use $\mathrm{CeO}_{2}$ in solar reactors. Perovskite oxides have not been employed so far in solar reactors for two-step WS purposes.

Recently, Nagahvi et al. [103] reported an interesting thermodynamic approach based on large solid-state entropy reduction, which can increase thermodynamic efficiency, such as that of metal oxides, with different entropy for two-phase thermochemical WS cycles and onsite electronic configuration entropy, which are generated by coupling orbital momentum $(l)$ and spin angular momentum $(s)$ in lanthanide f orbitals. Figure 9a shows the $f^{1}\left(\mathrm{Ce}^{3+}\right)$ energy-level splitting that occurs during spin-orbit coupling, with calculated crystal field. Without 

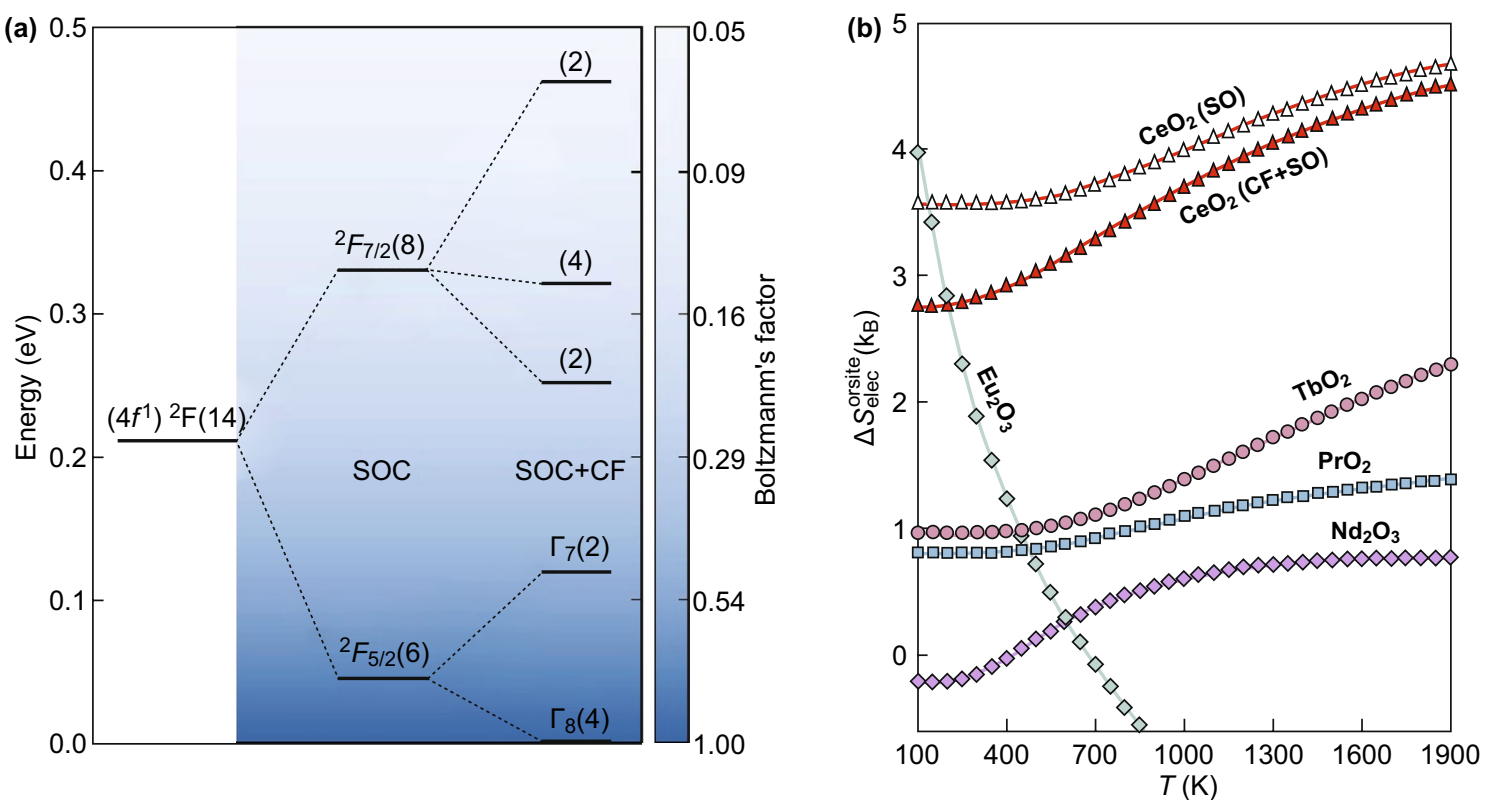

Fig. 9 a Energy levels of the $4 \mathrm{f}$ one orbital of $\mathrm{Ce}^{3+} \cdot \mathrm{Ce}^{3+}$ splits initially by spin orbit coupling and subsequently by cubic crystal field of the fluorite structure. b Calculated $S_{\text {elec }}^{\text {onsite }}$ for lanthanides ions. Reprinted with permission from Ref. [103], Copyright @ 2017, Springer Nature

crystal field, the $f^{1}$ states split into ${ }^{2} \mathrm{~F}_{5 / 2}$ and ${ }^{2} \mathrm{~F}_{7 / 2}$ separated by using approximately $0.28 \mathrm{eV}$. The crystal field interaction further splits the sixfold degenerate ${ }^{2} \mathrm{~F}_{5 / 2}$ ground state into a fourfold degenerate $\Gamma_{8}$ and twofold degenerate $\Gamma_{7}$ subsets, separated by $0.12 \mathrm{eV}$. Calculated crystal field by opposing crystal potential method for $\mathrm{Ce}^{3+}$ splits the eightfold ${ }^{2} \mathrm{~F}^{7 / 2}$ degenerate energy states with energies $0.25,0.32$, and $0.46 \mathrm{eV}$.

Myers and Graves [104] took out the electronic entropy involvement from absolute entropy data of lanthanide $\left(\mathrm{Ln}^{3+}\right)$ ions in lanthanide trihalides, which are comparable with the new approach of Naghavi et al. [103]. Having the energy $E_{i}$ and degeneracy $\left(g_{i}\right)$ of each microstate, $S_{\text {elec }}^{\text {onsite }}$ of a system with $\mathrm{m}$ different microstates was calculated by the following equation, where $p_{i}$ is the probability of thermal excitation and $Z$ is the partition function.

$$
\begin{aligned}
& S_{\text {elec }}^{\text {onsite }}=-k_{\mathrm{B}} \sum_{i}^{m} g_{i} p_{i} \ln p_{i} \\
& p_{i}=\frac{\exp \left(-E_{i} / k_{\mathrm{B}} T\right)}{Z} \\
& Z=\sum_{i}^{m} g_{i} \exp \left(-E_{i} / k_{\mathrm{B}} T\right)
\end{aligned}
$$

For thermochemical WS cycle applications, the electronic absolute entropy does not matter; the entropy difference only before $\left(f^{n}\right)$ and after $\left(f^{n+1}\right)$ reduction is relevant $S_{\text {elec }}^{\text {onsite }}=2\left(S_{\text {elec }}^{n-1}-S_{\text {elec }}^{n}\right)$. The factor two is due to the circumstance that two $\mathrm{Ce}^{4+}$ ions are reduced due to oxygen vacancy because of the large $S_{\text {elec }}^{\text {onsite }}$ gain in occupying one of an $f$-orbital. The electronic entropy of reduction in the twostep thermochemical WS cycle systems reaches its maximum, that is, the entropy of oxidized state is zero, $S_{\text {elec }}^{n}=0$. Using these criteria, Naghavi et al. [103] found largest $S_{\text {elec }}^{\text {onsite }}$ in $\mathrm{Ce}^{4+} \rightarrow \mathrm{Ce}^{3+}$, which undergoes an $f^{0} \rightarrow f^{1}$ redox reaction as shown in Fig. 9b. Having the oxidized state $f^{0}$ (1S) with zero onsite electronic entropy is a unique feature of ceria compared to any rare earth ration. The largest second value was found in terbium $\left(\mathrm{Tb}^{4+} \rightarrow \mathrm{Tb}^{3+}\right)$ because non-subtracted $\mathrm{Tb}^{4+}$ has half-filled shell levels with only eight spin-degenerate states $(2 S+1)$, but only one orbital ( $L=0$ ) degeneracy, while $\mathrm{Tb}^{3+}$ has an orbital degeneracy of $7(L=3)$, which provides additional entropy. This additional source of entropy may make $\mathrm{Tb}^{4+}$-based materials promising candidates for thermochemical WS cycle applications, since $\mathrm{Tb}$, like $\mathrm{Ce}$, is stable in two valence states $\left(\mathrm{Tb}^{4+} / \mathrm{Tb}^{3+}\right)$. 


\subsection{Solar WS by Enhancing Charge Separation Approach}

Photoelectronic WS is an attractive technique for producing $\mathrm{H}_{2}$ and $\mathrm{O}_{2}$ from water without causing pollution to the environment. Efficient and low-cost transformation of solar energy into a transportable storable form is an essential goal, and photoelectrochemical splitting of water into gas $\mathrm{H}_{2}$ and $\mathrm{O}_{2}$ is a promising solution. Solar photons $\mathrm{h} \vartheta$ with more than $1.23 \mathrm{eV}$ should be sufficient, depending on the free energy required to split the water. However, the required energy is significantly higher as a product of kinetic and thermodynamic non-ideals in the actual oxidation (occurring at the anode) and reduction (occurring at the cathode) reactions. Monoclinic clinobisvanite bismuth scheelite $\left(\mathrm{ms}^{\left.-\mathrm{BiVO}_{4}\right)}\right.$ has recently attracted a lot of attention because of its beneficial properties such as suitable conduction band-edge position, ability to withstand oxidation conditions, and material abundance [105] for ondemand oxygen production.

In addition, heterogeneous catalysts for the enlargement of oxygen are dominated by state-of-the-art metals, which dominate the noble metals (Ir or Ru), but their scarcity and high price have significant technological implications. Abundant and inexpensive first-row transition metal oxides are also water oxidation competent catalysts, although exclusively at very high $\mathrm{pH}$, or with auxiliary or ancillary electrolytes (i.e., phosphates) [106]. Alternatively, the Prussian blue-type material has emerged as a favorable catalyst for water oxidation catalysis $[107,108]$. These coordination polymers are: easy to process and obtain by using soft chemistry methods, available as nanoparticles/thin films, stable and active in a very large $\mathrm{pH}$ range, from neutral down to extremely acid conditions, and are non-toxic.

The unique performance of these catalysts is based on their structural and electronic characteristics. They are constructed from a hexasanomatolate anionic complex and a metal di-cation in stoichiometric addition. These coordination networks are very strong due to the strength of cyanide bridging, but with a rather high covalent character. Their structure is modeled after a face-centered cubic ideal network, but their nonstoichiometric nature creates many voids for solvent (water) and counter cations.

Recently, the ternary oxide $\mathrm{BiVO}_{4}$ topped all metal oxide photoanodes owing to a relatively small $(2.4 \mathrm{eV})$ band gap, which provided efficient light absorption, had reasonably negative conduction band edge $\left(\sim 0 \mathrm{~V}\right.$ vs. reversible $\mathrm{H}_{2}$ electrode), and allowed moderate charge transport properties [109]. Theoretically, the maximum water oxidation photocurrent $\left(J_{\max }\right)$ for $\mathrm{BiVO}_{4}$ photoanodes under 1.5 global air mass solar illumination is $7.5 \mathrm{~mA} \mathrm{~cm}^{-2}$ [109]. According to $J\left(\mathrm{H}_{2} \mathrm{O}\right)$, the practical water oxidation photocurrent $\left(\mathrm{J}\left(\mathrm{H}_{2} \mathrm{O}\right)\right)$ is considerably lower owing to the limited light absorption $\left(\eta_{\text {abs }}\right)$, charge separation $\left(\eta_{\text {sep }}\right)$, and surface charge transfer $\left(\eta_{\text {trans }}\right)$ efficiencies of the $\mathrm{BiVO}_{4}$ material; nevertheless $=J_{\text {max }} \times \eta_{\text {abs }} \times \eta_{\text {sep }} \times \eta_{\text {trans }}$ [33].

Various efforts were made to increase these capabilities. In particular, charge transfer efficiency $\eta_{\text {trans }}$ has been dramatically improved on the $\mathrm{BiVO}_{4}$ surface to improve water oxidation kinetics and/or surface malfunction by coating the oxygen oxidation reaction catalyst $[110,111]$. The charge separation efficiency $\eta_{\text {sep }}$ of $\mathrm{BiVO}_{4}$ has been improved in several ways, including the introduction of nanoscale porosity $[110,112]$, reduction of $\mathrm{BiVO}_{4}$ thickness [111], introduction of electron donors such as Mo and W [110, 113], and formation of a distributed homojunction by the starter of a gradient doping concentration of $\mathrm{W}$ in a $\mathrm{BiVO}_{4}$ film [114]. In addition, $\eta$ sep has been shown to improve the formation of heterogeneities of $\mathrm{BiVO}_{4}$ with other materials including films $\left(\mathrm{SnO}_{2}, \mathrm{SiO}_{2}, \mathrm{WO}_{3}\right.$, graphene) and nanowires $\left(\mathrm{WO}_{3}\right.$ and $\left.\mathrm{Fe}_{2} \mathrm{O}_{3}\right)$ [114].

Among the latest state-of-the-art $\mathrm{BiVO}_{4}$-based photoanoids, the highest efficiency was achieved by a doped $\mathrm{BiVO}_{4}$ film with gradient doping by $\mathrm{W}$ and an inherent $\mathrm{SnO}_{2}$ heterogenation, synthesized over a textured substrate, and cover coated with cobalt phosphate (CoPi). Oxygen evolution reaction catalysts have $\eta_{\text {abs }}, \eta_{\text {sep }}$, and $\eta_{\text {trans }}$, which were reported to have reversible water oxidation efficiencies of $1.23 \mathrm{~V}$ versus reversible $\mathrm{H}_{2}$ electrodes as 75,60 , and about $100 \%$, respectively [114]. Figure 10 shows the higher values of till date carrier-separation efficiency of the $\mathrm{W} / \mathrm{BiVO}_{4}$ homojunction reported by Abdi et al. [114], who reported that the use of dopant concentration differences is actually used to bend additional bands and thus to create/improve carrier separation. To fabricate a complete device for solar WS, which does not rely on externally applied bias potentials, they combined the stateof-the-art Co-Pi-W/BiVO 4 photoanode with a two-junction a-Si superstrate photovoltaic cell located behind the photoelectrochemical cell, as shown in Fig. 10a, b [114]. 
(a)

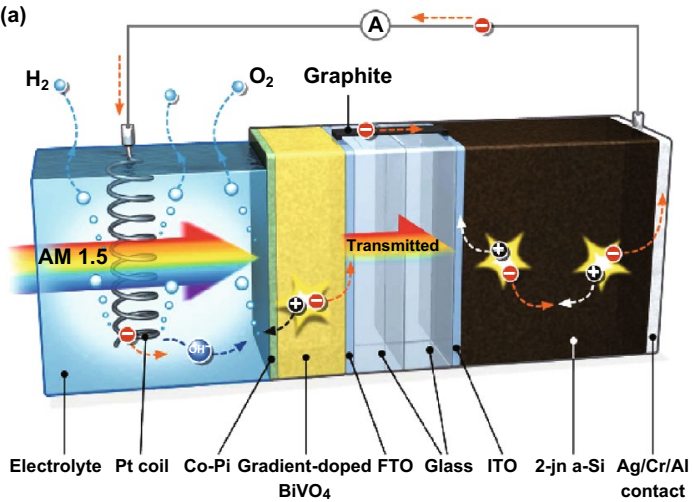

(b)

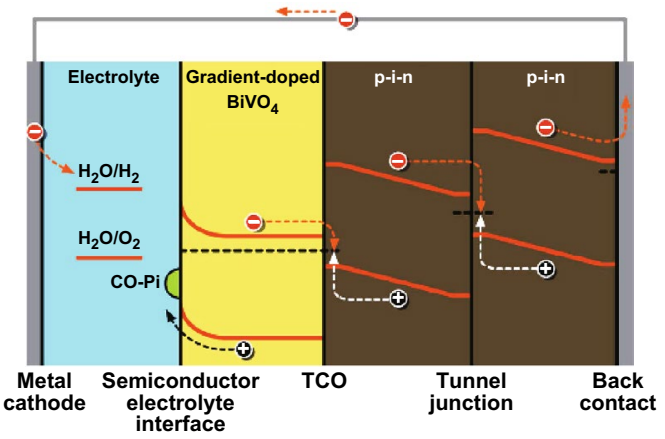

(c)

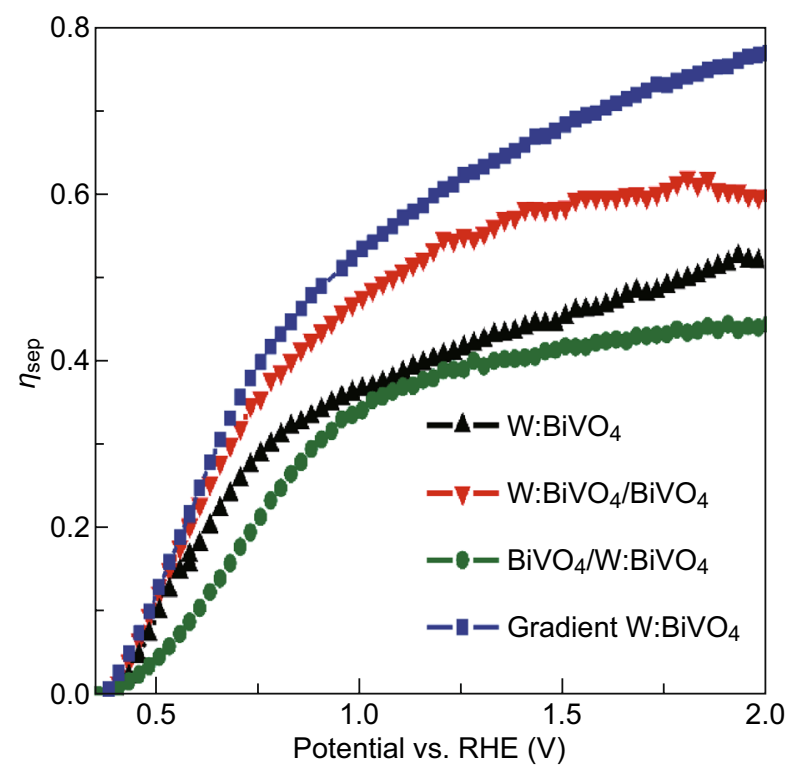

Fig. 10 a Schematic diagram of the combined device of gradient-doped $\mathrm{W} / \mathrm{BiVO}_{4}$ and a-Si solar cell. b The corresponding band diagram of the hybrid photoelectrode device. ITO tin-doped indium oxide, TCO transparent conducting oxide. c Carrier-separation efficiency $\left(\eta_{\text {sep }}\right)$ as a function of applied potential for $1 \% \mathrm{~W}$-doped $\mathrm{BiVO}_{4}$ (black triangle), $\mathrm{W} / \mathrm{BiVO}_{4}$ homojunction (red inverted triangle), $\mathrm{W} / \mathrm{BiVO} \mathrm{V}_{4}$ reverse homojunction (green circle), and gradient-doped $\mathrm{W}: \mathrm{BiVO}_{4}$ (blue square). Reprinted with permission from Ref. [114], Copyright @ 2013, Springer Nature

\subsection{Nanomaterials Designing Approach for WS}

Insulation and semiconductor nanostructures provide innumerable opportunities for manipulating/controlling the light at nanoscale. The higher their dielectric constant, the more strongly they interact with incident sunlight. When properly sized and shaped, they can also exhibit very strong optical resonances that can further promote light-to-light/light-matter interactions compared to bulk materials. It is significant to note that the strength of these resonances is similar to that found in metallic nanoparticles [115]. They can also occur in deep-subwavelength structures $(\sim 10 \mathrm{~nm})$ and have already enabled the performance improvement of nanoscale optoelectronic devices that can integrate with same size semiconductor electronic components [116]. Recently, the photovoltaic community has begun engineering these resonances with the aim of improving solar cell performance. Excitation of these resonances in semiconductor nanostructures can directly enhance useful absorption if semiconductor nanostructures are a fundamental part of the dynamical solar cell material or indirectly by enabling excitation of guided and diffracted resonances. The way in which light is absorbed or dispersed is determined and directed by the nature of the localized optical resonance that can be excited in a nanostructure. In order to engineer the paramount possible antireflection coatings and light trap layers, it is thus important to classify different types of local resonances and gain an intuitive understanding of their behavior.

However, the demonstrated solar-to- $\mathrm{H}_{2}$ conversion efficiency of the material to date is low which is basically strained by its smaller carrier diffusion length. Most commonly, the actual width of the photoelectrode film is determined by the lifespan time of carrier transport. The power to use built architectures to deposit a denser thick coating layer of photoactive materials photoactive materials is important for superior photoelectrochemical WS and alternative electrical phenomenon systems $[117,118]$. Nanocone structures are thought about in one in all the foremost promising candidates for high-efficiency skinny film electrical phenomenon [119]. However, few studies on nanocone-based 
photoelectrochemical devices have been explored, in particular with porous photoactive thin/thick layers on nanocone structures. In photoelectrochemical cells, photoactive coating layers deposited on a nanocone conductive substrate can not only improve the light absorption of photoactive materials, but also sustain efficient charge separation, provide a larger contact surface area, and promote surface water oxidation electrode/electrolyte interfaces.

Qiu et al. [21] reported an unambiguous strategy for the depressions of nearly 700-nm-thick nanoporous Mo-doped $\mathrm{BiVO}_{4}\left(\mathrm{Mo} / \mathrm{BiVO}_{4}\right)$ layer on engineered cone-shaped subnanostructures and demonstrated at low applied voltage that the exclusive photoanode attains a remarkable WS photocurrent with the best-reported solar-to- $\mathrm{H}_{2}$ conversion efficiency to date. The conductive nanocone substrate can accomplish efficient charge collection for the relatively thick film as shown in Fig. 11. In the aforementioned study, the authors introduced a thick coating of nanoporous photoabsorption layer through engineered cone-shaped nanostructures with an efficient higher charge separation, which resolved the immediate issue related to incompatibility of light absorption capacity with carrier transport length. The strategy of coating/depositing photoactive materials on engineered light-trapping architectures provides a technique for a new photoelectrode with high-performance photoelectrochemical WS cells [21].

Among the nanoparticle/nanotechnology-based electrodes used, WS- $\mathrm{Fe}_{2} \mathrm{O}_{3}$ (hematite) has occurred as one of the most promising materials $[120,121]$. Hematite is attracting widespread interest for use in photoelectrolysis of water for $\mathrm{H}_{2}$ production because iron is one of the least expensive and most abundant metals and has a high theoretical solar-to$\mathrm{H}_{2}$ conversion efficiency of $14-17 \%$ (based on the lower

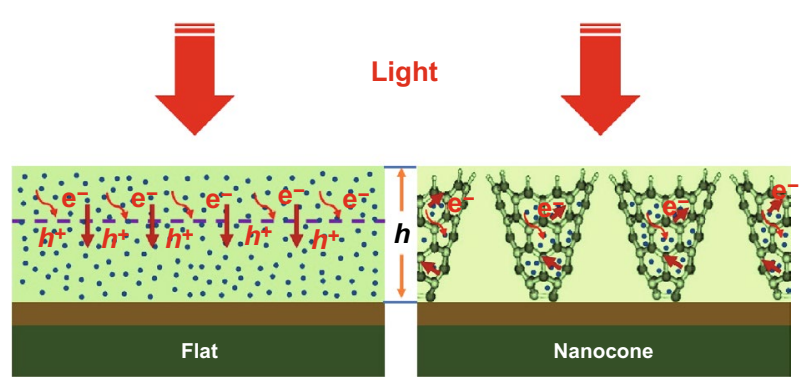

Fig. 11 Schematic illustration of the optical absorption mechanism and electron transport of nanoporous $\mathrm{BiVO}_{4}$ on the flat substrate and the conductive nanocone substrate [21] heating value of $\mathrm{H}_{2}$ ), which corresponds to a photocurrent of 11-14 $\mathrm{mA} \mathrm{cm}^{-2}$ [122]. Despite improvements in its performance as high as $3 \mathrm{~mA} \mathrm{~cm}{ }^{-2}$ under standard air mass and 1.5 illumination [123], structural features of hematite nanoparticle aggregates with the highest impact performance remain to be recognized by experimentation. In particular, although it has been projected that the reduction in electron-hole recombination in the synthesis of nanostructures with increasingly smaller dimensions will improve the photocurrent by decreasing electron-hole recombination [124], with nanostructure strategies, very little is acknowledged about the effect of such defects.

Recently, Warren et al. [125] developed an approach to correlate the spatial distribution of crystalline and currentcarrying domains in whole nanoparticle aggregates and they called this approach as nanoparticle-based $\mathrm{Fe}_{2} \mathrm{O}_{3}$ applied to electrodes that are interested in solar-to- $\mathrm{H}_{2}$ energy conversion. Their studies suggested that champions are nanoparticle aggregates that are largely liable for the high photocurrent for their experimental samples. The structure reported using conventional characterization techniques, including electron microscopy (Fig. 12a) and bright-field transmission electron canopy (Fig. 12b), is shown in Fig. 12 [125]. The dark-field transmission electron microscopy method was based on crystal-by-crystal imaging of entire nanocrystal aggregates, which provided information about the spatial distribution of high- and low-angle grain boundaries (Fig. 12c). Using atomic force microscopy, they measured the carrier charge transport characteristics of the majority of these nanoparticle aggregates (Fig. 12d) [125].

These champion nanoparticle aggregates may have photon-to-current capabilities that reach theoretical limits. If the structural properties of these aggregates can be understood more fully, there is a possibility that the difference between the reported new benchmark and theoretical maximum efficiency can be bridged. When electrodes are invented with a high quantity of these defender nanostructures, the electrodes accomplish the highest photocurrent of any metal oxide photoanode for photoelectrochemical WS under $100 \mathrm{~mW} \mathrm{~cm}^{-2}$ air mass and 1.5 illumination.

\subsection{Artificial Leap Approach for Solar WS}

To convert sunlight energy into chemical energy, the green leaf splits water through the photosynthetic natural process 

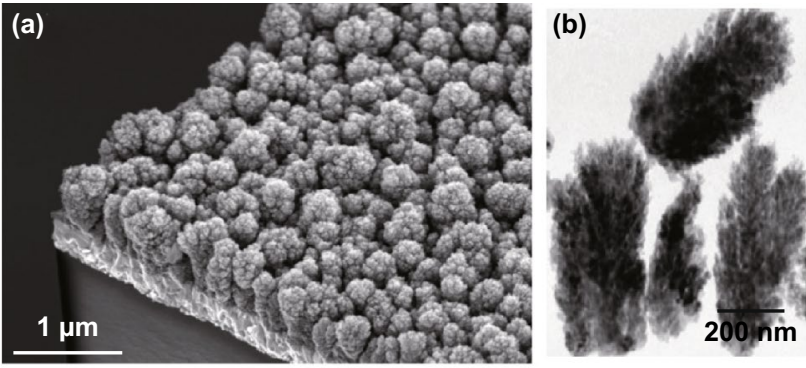

(c)



(d)

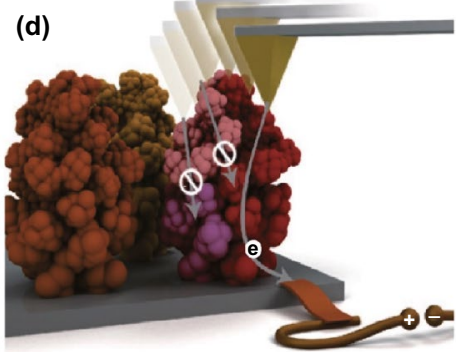

Fig. 12 Classical structure analysis by SEM, BF-TEM, and identification of champion nanostructures. a Cross-sectional SEM images show electrodes from a 45 viewing angle. b The areal densities of nanoparticle aggregates. c A DF-TEM analysis allows each region of a nanoparticle aggregate with a unique crystallographic orientation to be imaged separately. d Analysis by C-AFM examines the charge transport properties of individual nanostructures. Each color represents a different crystal orientation. Reprinted with permission from Ref. [125], Copyright @ 2012, American Chemical Society

to produce molecular oxygen and $\mathrm{H}_{2}$, which form separate protons and electrons. The primary stages of natural photosynthesis include absorption of sunlight and its conversion into spatially distinct electron-hole pairs. The holes in this wire-free photocurrent are occupied by $\mathrm{O}_{2}$ - evolving the complex of photosystem PSII to oxidize oxygen in the water. The proton and electron matrixes created as a by-product of a complex reaction that develops $\mathrm{O}_{2}$ are captured by ferredoxins of photosystem I. With the help of ferredoxin-nicotinamide adenine dinucleotide phosphate $\left(\mathrm{NADP}^{+}\right)$reductase, they are used to produce $\mathrm{H}_{2}$ in the form of nicotinamide adenine dinucleotide phosphate hydrogen (NADPH). To recognize the solar light energy conversion function of the leaf to produce a synthetic material, the light-absorbing material must capture/arrest a solar photon to generate/produce an electric current that is connected by the catalyst, which motivates the four electron/hole fuel-forming WS reaction under benign conditions and under 1 Sun $\left(100 \mathrm{~mW} \mathrm{~cm}^{-2}\right)$ illumination.

The compound that receives WS in photosynthesis is the $\mathrm{O}_{2}$ evolving complex, which resides in photosystem II. The oxygen-evolving complex is 'charged' by a solar-driven wireless current as shown in Fig. 13a [127]. Light absorption at the reaction center of the light mechanism photosystem PSII produces an electronically excited electron. The hole $(\times 4)$ resulting from electron transfer is passed within PS II to the oxygen-evolving complex, which performs the critical WS step to release $\mathrm{O}_{2}$ and four protons. The electrons are transferred/transported through a series of redox-active cofactors to photosystem I. These cofactors include plastoquinol and plastocyanin that bind within the cytochrome $b_{6} f$ (cyt $\left.b_{6} f\right)$ complex, finally arriving at ferredoxin bound to photosystem I (Fig. 13 a). Through ferredoxin-NADP ${ }^{+}$ reductase (FNR), these energized active electrons reduce protons to produce $\mathrm{H}_{2}$ in the form of NADPH [126]. In implementing these reaction sequences, the plant stores solar energy in a fuel-forming process resulting from rearranging the bonds of water.

An artificial leaf containing earth-abundant materials which works under ordinary conditions and at 1 Sun illumination has been realized by interfacing NiMoZn and CoOEC with a triple junction amorphous $\mathrm{Si}$ (3jn-a-Si) solar cell $[27,127]$.The ability to perform WS with Co-OEC and NiMoZn catalysts in natural waters, under ambient conditions, and at high and stable current densities provides a direct path to the creation of an artificial leaf, the design elements for which are shown in Fig. 13b [127]. The role of the photosynthetic membrane to capture solar light and convert it into a wireless current is assumed by Si. The photogenerated single electron and hole are relayed to the Co-OEC and NiMoZn catalysts, until the necessary four electron-hole equivalents are attained to drive the bond rearrangement of WS.

Some semiconductors with a large band gap provide sufficient energy-driving force (e.g., $E_{\mathrm{g}}>1.23 \mathrm{eV}$ ) as well as appropriate band-edge potentials to drive the overall WS process. Indeed, $\mathrm{TiO}_{2}\left(E_{\mathrm{g}} \sim 3.2 \mathrm{eV}\right)$ was the first material for WS applications [17]. Its conduction band-edge potential is $-0.17 \mathrm{~V}$ in comparison with the normal $\mathrm{H}_{2}$ electrode (NHE), which is adequately reductive for the $\mathrm{O}_{2}-\mathrm{H}_{2}$ evolution reaction (HER), whereas valence bandedge potential is $+3.03 \mathrm{~V}$, with NHE being substantially sufficient for $\mathrm{O}_{2}$ evolution reaction (OER). The same condition is identified and recognized for graphitic carbon nitrile $g-\mathrm{C}_{3} \mathrm{~N}_{4}, \mathrm{TaON}, \mathrm{CdS}, \mathrm{GaN}$ [128]. Thus, the simplest configuration of a non-natural leaf uses these wide band gap semiconductors as light harvesters. On the surface of 

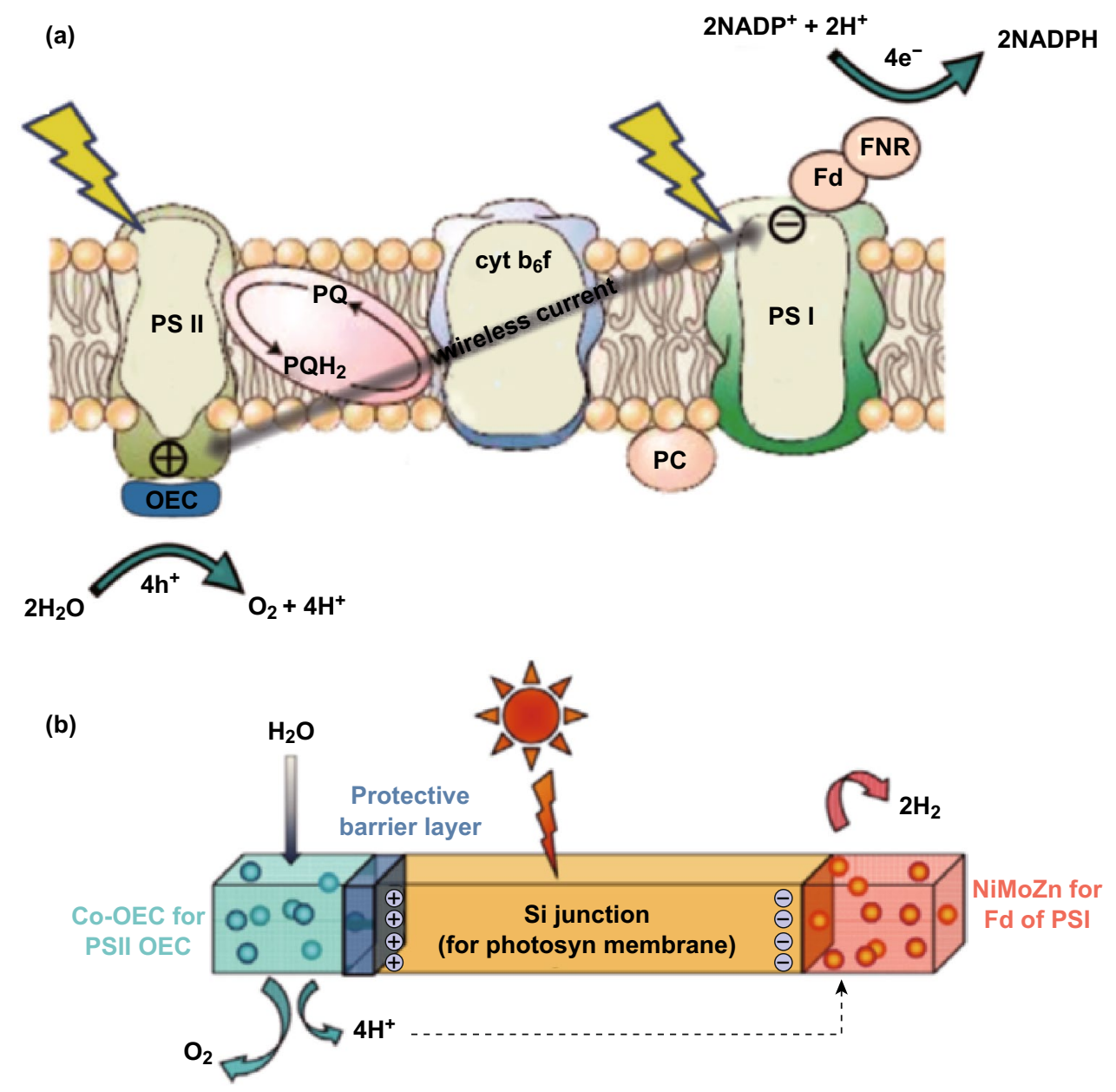

Fig. 13 a A simplified scheme of the light-driven reactions of photosynthesis. b Construction of an artificial leaf [127]

these light harvesters, two appropriately suitable catalysts for the HER and OER are loaded [129, 130]. This configuration was developed mainly as nanoparticles suspended in solution (Fig. 14a) but also as a freestanding electrode system [131]. However, it is worth noting these large band gap semiconductors can only harvest UV and near UV photons that constitute about $5 \%$ of the whole solar spectrum. Thus, low solar to $\mathrm{H}_{2}$ conversion yield, being less of $1 \%$, is usually expected.

Dual semiconductors having small or narrow band gaps were used to make artificial leaf. In fact, the natural photosynthesis coordination process chooses P680 and P700 chlorophyll, which exhibits a maximum absorption at wavelengths 680 and $700 \mathrm{~nm}$ as the dual light harvesters [130]. These are like an optical band gap of absorbent $E_{\mathrm{g}}$ of ca.1.8 eV. Inspired by this natural engineering, an artificial leaf is also proposed to be made up of two small or narrow band gap semiconductors (Fig. 14b). Photoanode is made of an n-type semiconductor, whereas p-type semiconductor was used to make the photocathode [132]. These two electrodes are wired/connected from side to side making ohmic contacts of high electrically conducting materials that have the appropriate work function level. Ideally, this contact material should exhibit a high transparency, so lightblocking phenomena are suppressed. Furthermore, when proton conductivity is disturbed, it is extremely demanding that ohmic contact materials should be implanted inside a proton exchange membrane such as Nafion ${ }^{\circledR}$. Basically, CNTs embedded within a Nafion ${ }^{\circledR}$ membrane were developed for a fuel cell of $\mathrm{H}_{2}$ proton exchange membrane [133]. 
(a)
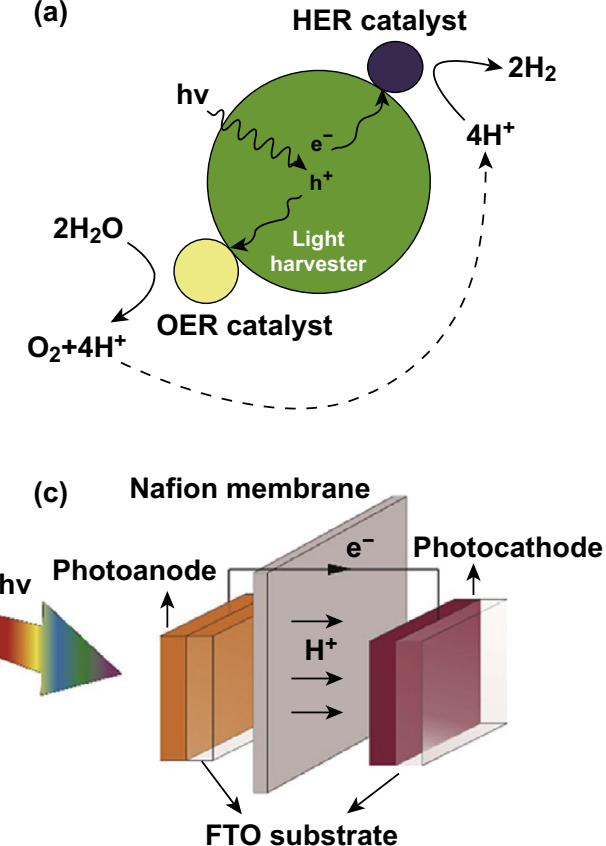

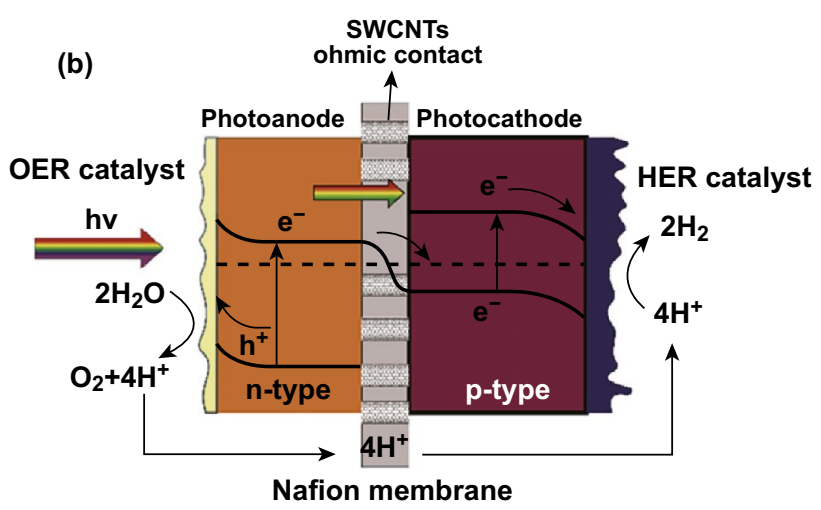

(d)

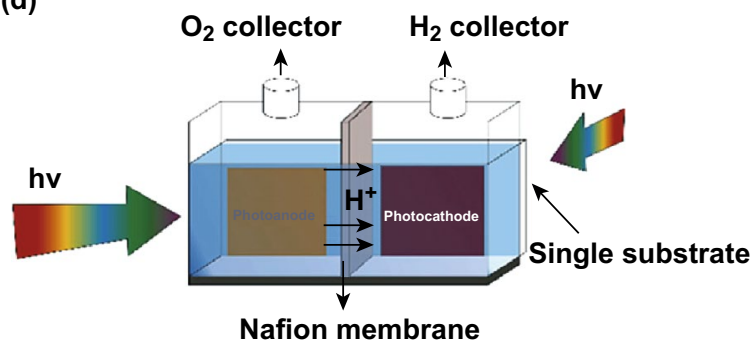

Fig. 14 Design of an artificial leaf prepared of a single semiconductor having huge band gap (a), a dual photoelectrodes that are assembled with a proton exchange membrane in the back-to-back configuration (b), a dual photoelectrodes wired (c), and a dual photoelectrodes loaded on a single support in the side-by-side configuration (d). The dual photoelectrodes in the three latter cases are made of semiconductors with small or narrow band gaps. Reprinted with permission from Ref. [131], Copyright 2017, Elsevier

Such membranes can be practical in principles, in artificial leaf engineering.

In fact, a complete artificial leaf design as described above (Fig. 14b) is still to be demonstrated. For instanced example, the photoanode and photocathode are loaded onto two different conducting substrates, for example, metal or translucent conducting oxides (TCO) such as fluorine (FTO)doped or indium (ITO)-doped tin oxides. These electrodes are then wired on another ohmic wire contact such as metal (Fig. 14c). The inclusion of two photoelectrodes on a single substrate can easily be made as a side-by-side mode (Fig. 14d). A back-to-back assemblage, being similar to the design described and labeled in Fig. 14b, represents a major challenge [131]. For this, it is necessary that both these electrodes are grown one by one, in a step-wise manner. In other words, photoanode should be grown under experimental conditions those are compatible for stability of the photocathode and vice-versa. In this framework, the advance development of a solution rolleroll process for photoelectrode fabrication, which employs ambient experimental conditions, may be a possible approach. To this end, learning from the creation of organic photovoltaic is a possibility.
Indeed, with this methodology, eye-catching advances have been reached for the fabrication of organic material-based photoelectrochemical or photoelectrodes cells [134-136].

An artificial leaf is designed through the simplest configuration and the dual combination of catalysts OER and $\mathrm{H}_{2}$ evolution HER reaction for photovoltaic and water electrolysis. Since the stability of a solar cell in water is indeed a major issue, this configuration allows photovoltaic cells

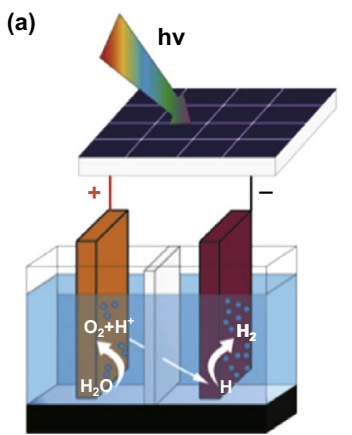

(b)

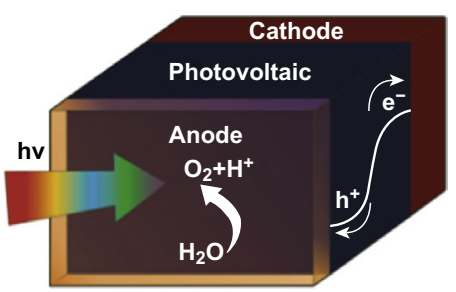

Fig. 15 Artificial leafs made of photovoltaics e water electrolyser assemblage: a wired and $\mathbf{b}$ wireless. Reprinted with permission from Ref. [131], Copyright 2017, Elsevier 
to be excluded from contact with water (Fig. 15a) [131]. The structure of a wire-free artificial leaf is further challenging the construction. To this end, the catalysts HER and OER must form the buried junction with the photovoltaic material (Fig. 15b). Because the photovoltaic must be immersed in water for operation in this case, there are challenges to identify suitable strategies to stabilize the photovoltaic material. Indeed, Si photovoltaic is easily oxidized in water when soluble $\mathrm{O}_{2}$ concentrations exceed 15 ppb [137]. However, along with air humidity, emerging organic-inorganic perovskite photovoltaic material is encountered due to rapid decomposition in contact with water [138].

\subsection{Challenge of Charge Transport Properties for WS}

The main target of this research is to produce high-efficient devices in the photoelectrochemical system, with low production cost and longer lifetime. In this context, designing a promising light absorber material that has favorable band alignment for water oxidation and possesses relatively long photocarrier lifetime is a mandatory requirement. This new material should not be restricted by poor carrier transport, deviations from ideal stoichiometry, and other defects. In particular, the selection of materials and approaches for future innovations is quite limited for surface protection, surface-state passivation, and selective charge extraction. New deposition approaches would be needed to fabricate promising materials that are semiconductor sensitive. For this purpose, extensive knowledge is required regarding interface energetics, the dynamic behaviors of interfaces during operation, and the electrolyte and temperature dependence of interface properties to design robust interfaces.

Although signification improvement has been made in this area in the past decade, constant developments are required for understanding surface and interface engineering properly to meet the demand for the progress of photoanodes with higher efficiencies in the practical application of photoelectrochemical WS. It is necessary to improve the understanding regarding the limitations of numerous surface modifications and how different parameters are involved in charge separation. The prediction of a right combination may be possible by understanding the transport mechanism of different semiconductors, thereby helping to reduce the risk that may arise because of ignoring potential materials and, in addition, helping to accelerate the progression of material screening. Finally, the problem related to charge transport could be solved by developing a strong theoretical base, in addition to knowledge regarding computational optimization and experimental skill. All of these would enable the designing of new materials for WS research.

\section{Conclusion and Future Prospects}

Several combinations of semiconductor materials, electrocatalysts, and cell configurations are available for photoelectrolysis research. As solar fuel research expands, standardization of research methods and characterization techniques for accurate reporting becomes paramount and ultimately helps the field move into new areas of development and discovery. The use of a dual (D4) band gap water splitting cell configuration, as opposed to the use of a monoband gap (S2) configuration for splitting of water, where the electric field is engendered at the semiconductor fluid junction or concluded a 'buried junction,' seems to be the furthermost effective and strong use of corresponding paired light-absorbing materials. Multiple junction configurations involve new contacts and new electrocatalysts. Semiconductor materials continue to develop and fully explain and optimize their many electrical properties. Recent efforts toward the development of capable photoelectrolysis equipment and advances help in controlling the size and shape of micro- and nanoscale features of semiconductors and catalysts. The use of structured photoelectrodes reduces material purity by controlling the directionality of charge movement and the light absorption pathways in semiconductors. High aspect ratio photoelectrode surfaces also might reduce the catalytic activities with the use of less expensive catalysts. The exploration for earth-abundant constituent materials that may be cast off in solar WS cells remains an essential target for inexpensive, globally, and ecofriendly benign approaches for energy conversion and storage. Stability of the photoelectrode remains to be a foremost challenge for the enlargement of competent photoanodes and photocathodes. Nature uses a regularly revived/renewed dual band gap photosystem to capture/arrest sunlight and store the energy in simple sugar molecules. A similar photoelectrochemical artificial strategy/approach can be recycled to decay water 
using two semiconductors and store/convert the energy in the simplest chemical bond $\mathrm{H}_{2}$.

Open Access This article is distributed under the terms of the Creative Commons Attribution 4.0 International License (http:// creativecommons.org/licenses/by/4.0/), which permits unrestricted use, distribution, and reproduction in any medium, provided you give appropriate credit to the original author(s) and the source, provide a link to the Creative Commons license, and indicate if changes were made.

\section{References}

1. R. Nebel, K.M. Macounová, H. Tarábková, L. Kavan, P. Krtil, Selectivity of photoelectrochemical water splitting on $\mathrm{TiO}_{2}$ anatase single crystals. J. Phys. Chem. C 123(17), 1085710867 (2019). https://doi.org/10.1021/acs.jpcc.8b11730

2. C.V. Reddy, K.R. Reddy, N.P. Shetti, J. Shim, T.M. Aminabhavi, D.D. Dionysiou, Hetero-nanostructured metal oxidebased hybrid photocatalysts for enhanced photoelectrochemical water splitting - a review. Int. J. Hydrog. Energy (2019). https://doi.org/10.1016/j.ijhydene.2019.02.109

3. H. Yu, L. Jiang, H. Wang, B. Huang, X. Yuan, J. Huang, J. Zhang, G. Zeng, Modulation of $\mathrm{Bi}_{2} \mathrm{MoO}_{6}$-based materials for photocatalytic water splitting and environmental application: a critical review. Small (2019). https://doi.org/10.1002/ smll.201901008

4. S. Pillai, M.A. Green, Plasmonics for photovoltaic applications. Solar Energy Mater. Solar Cells 94(9), 1481-1486 (2010). https://doi.org/10.1016/j.solmat.2010.02.046

5. T.J. Wydrzynski, W. Hillier (eds.), Molecular Solar Fuels (Royal Society of Chemistry, London, 2011). https://doi. org/10.1039/9781849733038

6. T.A. Faunce, W. Lubitz, A.W. Bill Rutherford, D. MacFarlane, G.F. Moore et al., Energy and environment policy case for a global project on artificial photosynthesis. Energy Environ. Sci. 6(3), 695-698 (2013). https://doi.org/10.1039/c3ee0 $0063 \mathrm{j}$

7. R.E. Blankenship, D.M. Tiede, J. Barber, G.W. Brudvig, G. Fleming et al., Comparing photosynthetic and photovoltaic efficiencies and recognizing the potential for improvement. Science 332(6031), 805-809 (2011). https://doi.org/10.1126/ science. 1200165

8. N. Armaroli, V. Balzani, Solar electricity and solar fuels: status and perspectives in the context of the energy transition. Chem. Eur. J. 22(1), 32-57 (2016). https://doi.org/10.1002/ chem. 201503580

9. Y. Tachibana, L. Vayssieres, J.R. Durrant, Artificial photosynthesis for solar water-splitting. Nat. Photon. 6(8), 511-518 (2012). https://doi.org/10.1038/nphoton.2012.175

10. B. Yao, J. Zhang, X. Fan, J. He, Y. Li, Surface engineering of nanomaterials for photo-electrochemical water splitting. Small 15(1), 1803746 (2019). https://doi.org/10.1002/ smll.201803746
11. Q. Zhang, D.T. Gangadharan, Y. Liu, Z. Xu, M. Chaker, D. $\mathrm{Ma}$, Recent advancements in plasmon-enhanced visible lightdriven water splitting. J. Materiomics 3(1), 33-50 (2017). https://doi.org/10.1016/j.jmat.2016.11.005

12. F. Jiang, T. Harada, Y. Kuang, T. Minegishi, K. Domen, S. Ikeda, $\mathrm{Pt} / \mathrm{In}_{2} \mathrm{~S}_{3} / \mathrm{CdS} / \mathrm{Cu}_{2} \mathrm{ZnSnS}_{4}$ thin film as an efficient and stable photocathode for water reduction under sunlight radiation. J. Am. Chem. Soc. 137(42), 13691-13697 (2015). https ://doi.org/10.1021/jacs.5b09015

13. P. Zhang, T. Wang, J. Gong, Mechanistic understanding of the plasmonic enhancement for solar water splitting. Adv. Mater. 27(36), 5328-5342 (2015). https://doi.org/10.1002/ adma. 201500888

14. J. Liu, Z. Wei, W. Shangguan, Defects engineering in photocatalytic water splitting materials. ChemCatChem 11, 1-14 (2019). https://doi.org/10.1002/cctc.201901579

15. X. Zou, Y. Zhang, Noble metal-free hydrogen evolution catalysts for water splitting. Chem. Soc. Rev. 44(15), 51485180 (2015). https://doi.org/10.1039/C4CS00448E

16. D. Kang, T.W. Kim, S.R. Kubota, A.C. Cardiel, H.G. Cha, K. Choi, Electrochemical synthesis of photoelectrodes and catalysts for use in solar water splitting. Chem. Rev. 115(23), 12839-12887 (2015). https://doi.org/10.1021/acs. chemrev.5b00498

17. A. Fujishima, K. Honda, Electrochemical photolysis of water at a semiconductor electrode. Nature 238(5358), 37-38 (1972). https://doi.org/10.1038/238037a0

18. M.G. Walter, E.L. Warren, J.R. McKone, S.W. Boettcher, Q. Mi, E.A. Santori, N.S. Lewism, Solar water splitting cells. Chem. Rev. 110(11), 6446-6473 (2010). https://doi. org/10.1021/cr1002326

19. C.G. Morales-Guio, S.D. Tilley, H. Vrubel, M. Grätzel, X. $\mathrm{Hu}$, Hydrogen evolution from a copper(I) oxide photocathode coated with an amorphous molybdenum sulphide catalyst. Nat. Commun. 5, 3059 (2014). https://doi.org/10.1038/ ncomms4059

20. T. Bak, J. Nowotny, M. Rekas, C.C. Sorrell, Photo-electrochemical hydrogen generation from water using solar energy. Materials-related aspects. Int. J. Hydrog. Energy 27(10), 991-1022 (2002). https://doi.org/10.1016/S0360 -3199(02)00022-8

21. Y. Qiu, W. Liu, W. Chen, W. Chen, G. Zhou et al., Efficient solar-driven water splitting by nanocone $\mathrm{BiVO}_{4}$-perovskite tandem cells. Sci. Adv. 2, e1501764 (2016). https://doi. org/10.1126/sciadv.1501764

22. Y. Chen, J.D. Prange, S. Dühnen, Y. Park, M. Gunji, C.E.D. Chidsey, P.C. McIntyre, Atomic layer-deposited tunnel oxide stabilizes silicon photoanodes for water oxidation. Nat. Mater. 10(7), 539-544 (2011). https://doi.org/10.1038/ nmat 3047

23. T.J. Jacobsson, V. Fjällström, M. Sahlberg, M. Edoff, T. Edvinsson, A monolithic device for solar water splitting based on series interconnected thin film absorbers reaching over 10\% solar-to-hydrogen efficiency. Energy Environ. Sci. 6(12), 3676-3683 (2013). https://doi.org/10.1039/c3ee4 $2519 \mathrm{c}$ 
24. C.R. Cox, J.Z. Lee, D.G. Nocera, T. Buonassisi, Ten-percent solar-to-fuel conversion with nonprecious materials. Proc. Natl. Acad. Sci. U.S.A. 111(39), 14057-14061 (2014). https ://doi.org/10.1073/pnas.1414290111

25. B.A. Pinaud, J.D. Benck, L.C. Seitz, A.J. Forman, Z. Chen et al., Technical and economic feasibility of centralized facilities for solar hydrogen production via photocatalysis and photoelectrochemistry. Energy Environ. Sci. 6(7), 1983-2002 (2013). https://doi.org/10.1039/c3ee40831k

26. C.A. Rodriguez, M.A. Modestino, D. Psaltis, C. Moser, Design and cost considerations for practical solar-hydrogen generators. Energy Environ. Sci. 7(12), 3828-3835 (2014). https://doi.org/10.1039/C4EE01453G

27. S.Y. Reece, J.A. Hamel, K. Sung, T.D. Jarvi, A.J. Esswein, J.J. Pijpers, D.G. Nocera, Wireless solar water splitting using silicon-based semiconductors and earth-abundant catalysts. Science 334(6056), 645-648 (2011). https://doi. org/10.1126/science. 1209816

28. A. Paracchino, V. Laporte, K. Sivula, M. Grätzel, E. Thimsen, Highly active oxide photocathode for photoelectrochemical water reduction. Nat. Mater. 10(6), 456-461 (2011). https://doi.org/10.1038/nmat3017

29. M.J. Kenney, M. Gong, Y. Li, J.Z. Wu, J. Feng, M. Lanza, H. Dai, High-performance silicon photoanodes passivated with ultrathin nickel films for water oxidation. Science 342(6160), 836-840 (2013). https://doi.org/10.1126/scien ce. 1241327

30. J. Luo, J. Im, M.T. Mayer, M. Schreier, M.K. Nazeeruddin et al., Water photolysis at $12.3 \%$ efficiency via perovskite photovoltaics and Earth-abundant catalysts. Science 345(6204), 1593-1596 (2014). https://doi.org/10.1126/scien ce. 1258307

31. M.A. Green, S. Pillai, Harnessing plasmonics for solar cells. Nat. Photon. 6(3), 130-132 (2012). https://doi.org/10.1038/ nphoton.2012.30

32. I. Thomann, B.A. Pinaud, Z. Chen, B.M. Clemens, T.F. Jaramillo, M.L. Brongersma, Plasmon enhanced solar-to-fuel energy conversion. Nano Lett. 11(8), 3440-3446 (2011). https://doi.org/10.1021/nl201908s

33. H. Dotan, K. Sivula, M. Grätzel, A. Rothschild, S.C. Warren, Probing the photoelectrochemical properties of hematite $\left(\alpha-\mathrm{Fe}_{2} \mathrm{O}_{3}\right)$ electrodes using hydrogen peroxide as a hole scavenger. Energy Environ. Sci. 4(3), 958-964 (2011). https://doi. org/10.1039/C0EE00570C

34. C. Hägglund, S.P. Apell, B. Kasemo, Maximized optical absorption in ultrathin films and its application to plasmonbased two-dimensional photovoltaics. Nano Lett. 10(8), 3135-3141 (2010). https://doi.org/10.1021/nl101929j

35. W. Ho, Reactions at metal surfaces induced by femtosecond lasers, tunneling electrons, and heating. J. Phys. Chem. 100(31), 13050-13060 (1996). https://doi.org/10.1021/jp953 5497

36. P. Christopher, H. Xin, S. Linic, Visible-light-enhanced catalytic oxidation reactions on plasmonic silver nanostructures. Nat. Chem. 3(6), 467-472 (2011). https://doi.org/10.1038/ nchem.1032
37. A.J. Morfa, K.L. Rowlen, T.H. Reilly, M.J. Romero, J. van de Lagemaat, Plasmon-enhanced solar energy conversion in organic bulk heterojunction photovoltaics. Appl. Phys. Lett. 92(1), 013504 (2008). https://doi.org/10.1063/1.2823578

38. O. Stenzel, A. Stendal, K. Voigtsberger, C. Von Borczyskowski, Enhancement of the photovoltaic conversion efficiency of copper phthalocyanine thin film devices by incorporation of metal clusters. Solar Energy Mater. Solar Cells 37(3-4), 337-348 (1995). https://doi.org/10.1016/09270248(95)00027-5

39. H.R. Stuart, D.G. Hall, Island size effects in nanoparticleenhanced photodetectors. Appl. Phys. Lett. 73(26), 38153817 (1998). https://doi.org/10.1063/1.122903

40. D.M. Schaadt, B. Feng, E.T. Yu, Enhanced semiconductor optical absorption via surface plasmon excitation in metal nanoparticles. Appl. Phys. Lett. 86(6), 063106 (2005). https ://doi.org/10.1063/1.1855423

41. S. Pillai, K.R. Catchpole, T. Trupke, M.A. Green, Surface plasmon enhanced silicon solar cells. J. Appl. Phys. 101(9), 093105 (2007). https://doi.org/10.1063/1.2734885

42. S.C. Warren, E. Thimsen, Plasmonic solar water splitting. Energy Environ. Sci. 5(1), 5133-5146 (2012). https://doi. org/10.1039/C1EE02875H

43. Z. Liu, W. Hou, P. Pavaskar, M. Aykol, S.B. Cronin, Plasmon resonant enhancement of photocatalytic water splitting under visible illumination. Nano Lett. 11(3), 1111-1116 (2011). https://doi.org/10.1021/nl104005n

44. Y. Wei, L. Ke, J. Kong, H. Liu, Z. Jiao et al., Enhanced photoelectrochemical water-splitting effect with a bent $\mathrm{ZnO}$ nanorod photoanode decorated with Ag nanoparticles. Nanotechnology 23(23), 235401 (2012). https://doi. org/10.1088/0957-4484/23/23/235401

45. R. Solarska, A. Królikowska, J. Augustyński, Silver nanoparticle induced photocurrent enhancement at $\mathrm{WO}_{3}$ photoanodes. Angew. Chem. Int. Ed. 49(43), 7980-7983 (2010). https://doi.org/10.1002/anie.201002173

46. X. Zhang, Y. Zhu, X. Yang, S. Wang, J. Shen, B. Lin, C. Li, Enhanced visible light photocatalytic activity of interlayerisolated triplex $\mathrm{Ag} @ \mathrm{SiO}_{2} @ \mathrm{TiO}_{2}$ core-shell nanoparticles. Nanoscale 5(8), 3359-3366 (2013). https://doi.org/10.1039/ c3nr00044c

47. D.B. Ingram, S. Linic, Water splitting on composite plasmonic-metal/semiconductor photoelectrodes: evidence for selective plasmon-induced formation of charge carriers near the semiconductor surface. J. Am. Chem. Soc. 133(14), 5202-5205 (2011). https://doi.org/10.1021/ja200086g

48. A. Kudo, Y. Miseki, Heterogeneous photocatalyst materials for water splitting. Chem. Soc. Rev. 38(1), 253-278 (2009). https://doi.org/10.1039/B800489G

49. R. Subbaraman, D. Tripkovic, D. Strmcnik, K.-C. Chang, M. Uchimura et al., Enhancing hydrogen evolution activity in water splitting by tailoring $\mathrm{Li}^{+}-\mathrm{Ni}(\mathrm{OH})_{2}-\mathrm{Pt}$ interfaces. Science 334(6060), 1256-1260 (2011). https://doi.org/10.1126/ science. 1211934

50. Y. Luo, L. Tang, U. Khan, Q. Yu, H. Cheng, X. Zou, B. Liu, Morphology and surface chemistry engineering toward 
pH-universal catalysts for hydrogen evolution at high current density. Nat. Commun. 10(1), 269 (2019). https://doi. org/10.1038/s41467-018-07792-9

51. T. Wang, Z. Luo, C. Li, J. Gong, Controllable fabrication of nanostructured materials for photoelectrochemical water splitting via atomic layer deposition. Chem. Soc. Rev. 43(22), 7469-7484 (2014). https://doi.org/10.1039/C3CS60370A

52. R. Liu, Z. Zheng, J. Spurgeon, X. Yang, Enhanced photoelectrochemical water-splitting performance of semiconductors by surface passivation layers. Energy Environ. Sci. 7(8), 2504-2517 (2014). https://doi.org/10.1039/C4EE00450G

53. F. Le Formal, N. Tetreault, M. Cornuz, T. Moehl, M. Grätzel, K. Sivula, Passivating surface states on water splitting hematite photoanodes with alumina overlayers. Chem. Sci. 2(4), 737-743 (2011). https://doi.org/10.1039/C0SC00578A

54. P. Zhang, T. Wang, J. Gong, Passivation of surface states by ALD-grown $\mathrm{TiO}_{2}$ overlayers on $\mathrm{Ta}_{3} \mathrm{~N}_{5}$ anodes for photoelectrochemical water oxidation. Chem. Commun. 52(57), 8806-8809 (2016). https://doi.org/10.1039/C6CC03411J

55. Z. Zhang, Q. Qian, B. Li, K.J. Chen, Interface engineering of monolayer $\mathrm{MoS}_{2} / \mathrm{GaN}$ hybrid heterostructure: modified band alignment for photocatalytic water splitting application by nitridation treatment. ACS Appl. Mater. Interfaces 10(20), 17419-17426 (2018). https://doi.org/10.1021/acsami.8b012 86

56. Z. Kang, H. Si, S. Zhang, J. Wu, Y. Sun, Q. Liao, Z. Zhang, Y. Zhang, Interface engineering for modulation of charge carrier behavior in $\mathrm{ZnO}$ photoelectrochemical water splitting. Adv. Funct. Mater. 29(15), 1808032 (2019). https://doi. org/10.1002/adfm.201808032

57. P. Niu, M. Qiao, Y. Li, L. Huang, T. Zhai, Distinctive defects engineering in graphitic carbon nitride for greatly extended visible light photocatalytic hydrogen evolution. Nano Energy 44, 73-81 (2018). https://doi.org/10.1016/j.nanoe n.2017.11.059

58. S. Bai, N. Zhang, C. Gao, Y. Xiong, Defect engineering in photocatalytic materials. Nano Energy 53, 296-336 (2018). https://doi.org/10.1016/j.nanoen.2018.08.058

59. X. Chen, L. Liu, Y. Yu Peter, S.S. Mao, Increasing solar absorption for photocatalysis with black hydrogenated titanium dioxide nanocrystals. Science 331(6018), 746-750 (2011). https://doi.org/10.1126/science.1200448

60. F. Lei, Y. Sun, K. Liu, S. Gao, L. Liang, B. Pan, Y. Xie, Oxygen vacancies confined in ultrathin indium oxide porous sheets for promoted visible-light water splitting. J. Am. Chem. Soc. 136(19), 6826-6829 (2014). https://doi. org/10.1021/ja501866r

61. S.U.M. Khan, M. Al-Shahry, W.B. Ingler, Efficient photochemical water splitting by a chemically modified n- $\mathrm{TiO}_{2}$. Science 297(5590), 2243-2245 (2002). https://doi. org/10.1126/science. 1075035

62. F. Zuo, K. Bozhilov, R.J. Dillon, L. Wang, P. Smith, X. Zhao, C. Bardeen, P. Feng, Active facets on titanium(III)doped TiO2: an effective strategy to improve the visible-light photocatalytic activity. Angew. Chem. Int. Ed. 51(25), 62236226 (2012). https://doi.org/10.1002/anie.201202191

63. Z. Wang, C. Yang, T. Lin, H. Yin, P. Chen et al., Visible-light photocatalytic, solar thermal and photoelectrochemical properties of aluminium-reduced black titania. Energy Environ. Sci. 6(10), 3007-3014 (2013). https://doi.org/10.1039/c3ee4 $1817 \mathrm{k}$

64. H. Wang, L. Jia, P. Bogdanoff, S. Fiechter, H. Möhwald, D. Shchukin, Size-related native defect engineering in high intensity ultrasonication of nanoparticles for photoelectrochemical water splitting. Energy Environ. Sci. 6(3), 799-804 (2013). https://doi.org/10.1039/c3ee24058d

65. L. Shi, W. Zhou, Z. Li, S. Koul, A. Kushima, Y. Yang, Periodically ordered nanoporous perovskite photoelectrode for efficient photoelectrochemical water splitting. ACS Nano 12(6), 6335-6342 (2018). https://doi.org/10.1021/acsnano.8b03940

66. G. Wang, Y. Yang, Y. Ling, H. Wang, X. Lu et al., An electrochemical method to enhance the performance of metal oxides for photoelectrochemical water oxidation. J. Mater. Chem. A 4(8), 2849-2855 (2016). https://doi.org/10.1039/C5TA1 $0477 \mathrm{G}$

67. G. Wang, H. Wang, Y. Ling, Y. Tang, X. Yang et al., Hydrogen-treated $\mathrm{TiO}_{2}$ nanowire arrays for photoelectrochemical water splitting. Nano Lett. 11(7), 3026-3033 (2011). https:// doi.org/10.1021/nl201766h

68. I.S. Cho, M. Logar, C.H. Lee, L. Cai, F.B. Prinz, X. Zheng, Rapid and controllable flame reduction of $\mathrm{TiO}_{2}$ nanowires for enhanced solar water-splitting. Nano Lett. 14(1), 24-31 (2013). https://doi.org/10.1021/nl4026902

69. J.-W. Jang, C. Du, Y. Ye, Y. Lin, X. Yao et al., Enabling unassisted solar water splitting by iron oxide and silicon. Nat. Commun. 6, 7447 (2015). https://doi.org/10.1038/ncomm s8447

70. Y. Umena, K. Kawakami, J. Shen, N. Kamiya, Crystal structure of oxygen-evolving photosystem II at a resolution of 1.9 Å. Nature 473(7345), 55-60 (2011). https://doi.org/10.1038/ nature09913

71. K.N. Ferreira, T.M. Iverson, K. Maghlaoui, J. Barber, S. Iwata, Architecture of the photosynthetic oxygen-evolving center. Science 303(5665), 1831-1838 (2004). https://doi. org/10.1126/science.1093087

72. A.J. Bard, Photoelectrochemistry and heterogeneous photocatalysis at semiconductors. J. Photochem. 10(1), 59-75 (1979). https://doi.org/10.1016/0047-2670(79)80037-4

73. H. Kato, M. Hori, R. Konta, Y. Shimodaira, A. Kudo, Construction of Z-scheme type heterogeneous photocatalysis systems for water splitting into $\mathrm{H}_{2}$ and $\mathrm{O}_{2}$ under visible light irradiation. Chem. Lett. 33(10), 1348-1349 (2004). https:// doi.org/10.1246/cl.2004.1348

74. D.J. Martin, P.J.T. Reardon, S.J.A. Moniz, J. Tang, Visible light-driven pure water splitting by a nature-inspired organic semiconductor-based system. J. Am. Chem. Soc. 136(36), 12568-12571 (2014). https://doi.org/10.1021/ja506386e

75. C. Liu, B.C. Colón, M. Ziesack, P.A. Silver, D.G. Nocera, Water splitting-biosynthetic system with $\mathrm{CO}_{2}$ reduction 
efficiencies exceeding photosynthesis. Science 352(6290), 1210-1213 (2016). https://doi.org/10.1126/science.aaf5039

76. A.C. Walters, T.G. Perring, J.-S. Caux, A.T. Savici, G.D. Gu, C.-C. Lee, W. Ku, I.A. Zaliznyak, Effect of covalent bonding on magnetism and the missing neutron intensity in copper oxide compounds. Nat. Phys. 5(12), 867 (2009). https://doi. org/10.1038/nphys1405

77. Z. Chen, T.F. Jaramillo, T.G. Deutsch, A. Kleiman-Shwarsctein, A.J. Forman et al., Accelerating materials development for photoelectrochemical hydrogen production: standards for methods, definitions, and reporting protocols. J. Mater. Res. 25(1), 3-16 (2010). https://doi.org/10.1557/ JMR.2010.0020

78. M.F. Weber, M.J. Dignam, Efficiency of splitting water with semiconducting photoelectrodes. J. Electrochem. Soc. 131(6), 1258-1265 (1984). https://doi.org/10.1149/1.2115797

79. J.R. Bolton, S.J. Strickler, J.S. Connolly, Limiting and realizable efficiencies of solar photolysis of water. Nature 316(6028), 495-500 (1985). https://doi.org/10.1038/31649 $5 \mathrm{a} 0$

80. R.E. Rocheleau, E.L. Miller, Photoelectrochemical production of hydrogen: engineering loss analysis. Int. J. Hydrog. Energy 22(8), 771-782 (1997). https://doi.org/10.1016/S0360 $-3199(96) 00221-2$

81. S. Chen, L. Wang, Thermodynamic oxidation and reduction potentials of photocatalytic semiconductors in aqueous solution. Chem. Mater. 24(18), 3659-3666 (2012). https://doi. org/10.1021/cm302533s

82. J. Greeley, T.F. Jaramillo, J. Bonde, I.B. Chorkendorff, J.K. Nørskov, Computational high-throughput screening of electrocatalytic materials for hydrogen evolution. Mater. Sustain. Energy (2010). https://doi.org/10.1142/9789814317 665_0041

83. R. van de Krol, Y. Liang, J. Schoonman, Solar hydrogen production with nanostructured metal oxides. J. Mater. Chem. 18(20), 2311-2320 (2008). https://doi.org/10.1039/b718969a

84. A.V. Akimov, A.J. Neukirch, O.V. Prezhdo, Theoretical insights into photoinduced charge transfer and catalysis at oxide interfaces. Chem. Rev. 113(6), 4496-4565 (2013). https ://doi.org/10.1021/cr3004899

85. P. Liao, E.A. Carter, New concepts and modeling strategies to design and evaluate photo-electro-catalysts based on transition metal oxides. Chem. Soc. Rev. 42(6), 2401-2422 (2013). https://doi.org/10.1039/C2CS35267B

86. L.C. Seitz, Z. Chen, A.J. Forman, B.A. Pinaud, J.D. Benck, T.F. Jaramillo, Modeling practical performance limits of photoelectrochemical water splitting based on the current state of materials research. Chemsuschem 7(5), 1372-1385 (2014). https://doi.org/10.1002/cssc.201301030

87. H. Cheng, A. Selloni, Hydroxide ions at the water/anatase $\mathrm{TiO}_{2}(101)$ interface: structure and electronic states from first principles molecular dynamics. Langmuir 26(13), 1151811525 (2010). https://doi.org/10.1021/la100672f

88. J. Cheng, M. Sprik, The electric double layer at a rutile $\mathrm{TiO}_{2}$ water interface modelled using density functional theory based molecular dynamics simulation. J. Phys.: Condens.
Matter 26(24), 244108 (2014). https://doi.org/10.1088/0953$8984 / 26 / 24 / 244108$

89. A. Laio, F.L. Gervasio, Metadynamics: a method to simulate rare events and reconstruct the free energy in biophysics, chemistry and material science. Rep. Prog. Phys. 71(12), 126601 (2008). https://doi.org/10.1088/00344885/71/12/126601

90. M. Otani, O. Sugino, First-principles calculations of charged surfaces and interfaces: a plane-wave nonrepeated slab approach. Phys. Rev. B 73(11), 115407 (2006). https://doi. org/10.1103/PhysRevB.73.115407

91. D. Opalka, T.A. Pham, M. Sprik, G. Galli, Electronic energy levels and band alignment for aqueous phenol and phenolate from first principles. J. Phys. Chem. B 119(30), 9651-9660 (2015). https://doi.org/10.1021/acs.jpcb.5b041 89

92. A.P. Gaiduk, M. Govoni, R. Seidel, J.H. Skone, B. Winter, G. Galli, Photoelectron spectra of aqueous solutions from first principles. J. Am. Chem. Soc. 138(22), 6912-6915 (2016). https://doi.org/10.1021/jacs.6b00225

93. T.W. Kim, Y. Ping, G.A. Galli, K.-S. Choi, Simultaneous enhancements in photon absorption and charge transport of bismuth vanadate photoanodes for solar water splitting. Nat. Commun. 6, 8769 (2015). https://doi.org/10.1038/ncomm s9769

94. M. Pastore, F. De Angelis, First-principles modeling of a dye-sensitized $\mathrm{TiO}_{2} / \mathrm{IrO}_{2}$ photoanode for water oxidation. J. Am. Chem. Soc. 137(17), 5798-5809 (2015). https://doi. org/10.1021/jacs.5b02128

95. G.P. Smestad, A. Steinfeld, Review: photochemical and thermochemical production of solar fuels from $\mathrm{H}_{2} \mathrm{O}$ and $\mathrm{CO}_{2}$ using metal oxide catalysts. Ind. Eng. Chem. Res. 51(37), 11828-11840 (2012). https://doi.org/10.1021/ie3007962

96. C.N.R. Rao, S. Dey, Generation of $\mathrm{H}_{2}$ and $\mathrm{CO}$ by solar thermochemical splitting of $\mathrm{H}_{2} \mathrm{O}$ and $\mathrm{CO}_{2}$ by employing metal oxides. J. Solid State Chem. 242, 107-115 (2016). https://doi. org/10.1016/j.jssc.2015.12.018

97. T. Kodama, N. Gokon, Thermochemical cycles for hightemperature solar hydrogen production. Chem. Rev. 107(10), 4048-4077 (2007). https://doi.org/10.1021/cr050188a

98. T. Nakamura, Hydrogen production from water utilizing solar heat at high temperatures. Sol. Energy 19(5), 467-475 (1977). https://doi.org/10.1016/0038-092X(77)90102-5

99. J. Kim, C.A. Henao, T.A. Johnson, D.E. Dedrick, J.E. Miller, E.B. Stechel, C.T. Maravelias, Methanol production from $\mathrm{CO}_{2}$ using solar-thermal energy: process development and techno-economic analysis. Energy Environ. Sci. 4(9), 31223132 (2011). https://doi.org/10.1039/c1ee01311d

100. C.N.R. Rao, S. Dey, Solar thermochemical splitting of water to generate hydrogen. Proc. Natl. Acad. Sci. U.S.A. 114(51), 13385-13393 (2017). https://doi.org/10.1073/pnas.17001 04114

101. C.L. Muhich, B.D. Ehrhart, I. Al-Shankiti, B.J. Ward, C.B. Musgrave, A.W. Weimer, A review and perspective of efficient hydrogen generation via solar thermal water splitting. 
Wires Energy Environ. 5(3), 261-287 (2016). https://doi. org/10.1002/wene. 174

102. C. Agrafiotis, M. Roeb, C. Sattler, A review on solar thermal syngas production via redox pair-based water/carbon dioxide splitting thermochemical cycles. Renew. Sustain. Energy Rev. 42, 254-285 (2015). https://doi.org/10.1016/j. rser.2014.09.039

103. S.S. Naghavi, A.A. Emery, H.A. Hansen, F. Zhou, V. Ozolins, C. Wolverton, Giant onsite electronic entropy enhances the performance of ceria for water splitting. Nat. Commun. 8(1), 285 (2017). https://doi.org/10.1038/s41467-017-00381-2

104. C.E. Myers, D.T. Graves, Vaporization thermodynamics of lanthanide trihalides. J. Chem. Eng. Data 22(4), 440-445 (1977). https://doi.org/10.1021/je60075a023

105. P. Chakthranont, L.C. Seitz, T.F. Jaramillo, Mapping photoelectrochemical current distribution at nanoscale dimensions on morphologically controlled $\mathrm{BiVO}_{4}$. J. Phys. Chem. Lett. 6(18), 3702-3707 (2015). https://doi.org/10.1021/acs. jpclett.5b01587

106. J.B. Gerken, J.G. McAlpin, J.Y.C. Chen, M.L. Rigsby, W.H. Casey, R.D. Britt, S.S. Stahl, Electrochemical water oxidation with cobalt-based electrocatalysts from $\mathrm{pH}$ 0-14: the thermodynamic basis for catalyst structure, stability, and activity. J. Am. Chem. Soc. 133(36), 14431-14442 (2011). https://doi.org/10.1021/ja205647m

107. S. Pintado, S. Goberna-Ferrón, E.C. Escudero-Adán, J.R. Galán-Mascarós, Electrochemical water oxidation with cobalt-based electrocatalysts from $\mathrm{pH} 0-14$ : the thermodynamic basis for catalyst structure, stability, and activity. J. Am. Chem. Soc. 135(36), 13270-13273 (2013). https:// doi.org/10.1021/ja406242y

108. Y. Yamada, K. Oyama, R. Gates, S. Fukuzumi, High catalytic activity of heteropolynuclear cyanide complexes containing cobalt and platinum ions: visible-light driven water oxidation. Angew. Chem. Int. Ed. 54(19), 5613-5617 (2015). https://doi.org/10.1002/anie.201501116

109. Y. Park, K.J. McDonald, K.-S. Choi, Progress in bismuth vanadate photoanodes for use in solar water oxidation. Chem. Soc. Rev. 42(6), 2321-2337 (2013). https://doi. org/10.1039/C2CS35260E

110. D.K. Zhong, S. Choi, D.R. Gamelin, Near-complete suppression of surface recombination in solar photoelectrolysis by "Co-Pi" catalyst-modified W:BiVO 4 . J. Am. Chem. Soc. 133(45), 18370-18377 (2011). https://doi.org/10.1021/ ja207348x

111. K.J. McDonald, K.-S. Choi, A new electrochemical synthesis route for a $\mathrm{BiOI}$ electrode and its conversion to a highly efficient porous $\mathrm{BiVO}_{4}$ photoanode for solar water oxidation. Energy Environ. Sci. 5(9), 8553-8557 (2012). https://doi.org/10.1039/c2ee22608a

112. J.A. Seabold, K.-S. Choi, Efficient and stable photo-oxidation of water by a bismuth vanadate photoanode coupled with an iron oxyhydroxide oxygen evolution catalyst. J. Am. Chem. Soc. 134(4), 2186-2192 (2012). https://doi. org/10.1021/ja209001d
113. S.K. Pilli, T.E. Furtak, L.D. Brown, T.G. Deutsch, J.A. Turner, A.M. Herring, Cobalt-phosphate $(\mathrm{Co}-\mathrm{Pi})$ catalyst modified Mo-doped $\mathrm{BiVO}_{4}$ photoelectrodes for solar water oxidation. Energy Environ. Sci. 4(12), 5028-5034 (2011). https://doi.org/10.1039/c1ee02444b

114. F.F. Abdi, L. Han, A.H.M. Smets, M. Zeman, B. Dam, R. Van De Krol, Efficient solar water splitting by enhanced charge separation in a bismuth vanadate-silicon tandem photoelectrode. Nat. Commun. 4, 2195 (2013). https://doi. org/10.1038/ncomms3195

115. C.F. Bohren, D.R. Huffman, Z. Kam, Scattered thoughts. Nature 306, 625 (1983). https://doi.org/10.1038/306625a0

116. L. Cao, J.S. White, J.-S. Park, J.A. Schuller, B.M. Clemens, M.L. Brongersma, Engineering light absorption in semiconductor nanowire devices. Nat. Mater. 8(8), 643 (2009). https://doi.org/10.1038/nmat2477

117. F. Boudoire, R. Toth, J. Heier, A. Braun, E.C. Constable, Photonic light trapping in self-organized all-oxide microspheroids impacts photoelectrochemical water splitting. Energy Environ. Sci. 7(8), 2680-2688 (2014). https://doi. org/10.1039/C4EE00380B

118. K.X. Wang, Z. Yu, V. Liu, A. Raman, Y. Cui, S. Fan, Light trapping in photonic crystals. Energy Environ. Sci. 7(8), 2725-2738 (2014). https://doi.org/10.1039/C4EE00839A

119. M.L. Brongersma, Y. Cui, S. Fan, Light management for photovoltaics using high-index nanostructures. Nat. Mater. 13(5), 451-460 (2014). https://doi.org/10.1038/nmat3921

120. J. Brillet, J. Yum, M. Cornuz, T. Hisatomi, R. Solarska et al., Highly efficient water splitting by a dual-absorber tandem cell. Nat. Photon. 6(12), 824-828 (2012). https://doi. org/10.1038/nphoton.2012.265

121. L. Li, Y. Yu, F. Meng, Y. Tan, R.J. Hamers, S. Jin, Facile solution synthesis of $\alpha-\mathrm{FeF}_{3} \cdot 3 \mathrm{H}_{2} \mathrm{O}$ nanowires and their conversion to $\alpha-\mathrm{Fe}_{2} \mathrm{O}_{3}$ nanowires for photoelectrochemical application. Nano Lett. 12(2), 724-731 (2012). https://doi. org/10.1021/nl2036854

122. L.A. Marusak, R. Messier, W.B. White, Optical absorption spectrum of hematite, $\alpha \mathrm{Fe}_{2} \mathrm{O}_{3}$ near IR to UV. J. Phys. Chem. Solids 41(9), 981-984 (1980). https://doi.org/10.1016/00223697(80)90105-5

123. A. Kay, I. Cesar, M. Grätzel, New benchmark for water photooxidation by nanostructured $\alpha-\mathrm{Fe}_{2} \mathrm{O}_{3}$ films. J. Am. Chem. Soc. 128(49), 15714-15721 (2006). https://doi.org/10.1021/ ja0643801

124. E. Thimsen, F. Le Formal, M. Gratzel, S.C. Warren, Influence of plasmonic Au nanoparticles on the photoactivity of $\mathrm{Fe}_{2} \mathrm{O}_{3}$ electrodes for water splitting. Nano Lett. 11(1), 35-43 (2010). https://doi.org/10.1021/n11022354

125. S.C. Warren, K. Voïtchovsky, H. Dotan, C.M. Leroy, M. Cornuz et al., Identifying champion nanostructures for solar water-splitting. Nat. Mater. 12(9), 842-849 (2013). https:// doi.org/10.1038/nmat3684

126. J. Barber, Hydrogen derived from water as a sustainable solar fuel: learning from biology. Sustain. Energy Fuels 2(5), 927935 (2018). https://doi.org/10.1039/C8SE00002F 
127. D.G. Nocera, The artificial leaf. Acc. Chem. Res. 45(5), 767-776 (2012). https://doi.org/10.1021/ar2003013

128. T. Hisatomi, J. Kubota, K. Domen, Recent advances in semiconductors for photocatalytic and photoelectrochemical water splitting. Chem. Soc. Re. 43(22), 7520-7535 (2014). https:// doi.org/10.1039/C3CS60378D

129. K. Maeda, K. Teramura, D. Lu, N. Saito, Y. Inoue, K. Domen, Noble-metal/Cr2O3 core/shell nanoparticles as a cocatalyst for photocatalytic overall water splitting. Angew. Chem. Int. Ed. 45(46), 7806-7809 (2006). https://doi.org/10.1002/ anie. 200602473

130. C. Pan, T. Takata, M. Nakabayashi, T. Matsumoto, N. Shibata, Y. Ikuhara, K. Domen, A complex perovskite-type oxynitride: the first photocatalyst for water splitting operable at up to $600 \mathrm{~nm}$. Angew. Chem. Int. Ed. 54(10), 2955-2959 (2015). https://doi.org/10.1002/anie.201410961

131. P.D. Nguyen, T.M. Duong, P.D. Tran, Current progress and challenges in engineering viable artificial leaf for solar water splitting. J. Sci.: Adv. Mater. Dev. 2, 399-417 (2017). https:// doi.org/10.1016/j.jsamd.2017.08.006

132. J. Barber, Photosynthetic energy conversion: natural and artificial. Chem. Soc. Rev. 38(1), 185-196 (2009). https://doi. org/10.1039/B802262N

133. Y. Liu, B. Yi, Z. Shao, D. Xing, H. Zhang, Carbon nanotubes reinforced nafion composite membrane for fuel cell applications. Electrochem. Solid-State Lett. 9(7), A356-A359 (2006). https://doi.org/10.1149/1.2203230
134. M. Haro, C. Solis, G. Molina, L. Otero, J. Bisquert, S. Gimenez, A. Guerrero, Toward stable solar hydrogen generation using organic photoelectrochemical cells. J. Phys. Chem. C 119(12), 6488-6494 (2015). https://doi.org/10.1021/acs. jpcc. 5 b01420

135. T. Bourgeteau, D. Tondelier, B. Geffroy, R. Brisse, C. Laberty-Robert et al., $\mathrm{A} \mathrm{H}_{2}$-evolving photocathode based on direct sensitization of $\mathrm{MoS}_{3}$ with an organic photovoltaic cell. Energy Environ. Sci. 6(9), 2706-2713 (2013). https:// doi.org/10.1039/c3ee41321g

136. H.C. Rojas, S. Bellani, F. Fumagalli, G. Tullii, S. Leonardi et al., Polymer-based photocathodes with a solution-processable cuprous iodide anode layer and a polyethyleneimine protective coating. Energy Environ. Sci. 9(12), 3710-3723 (2016). https://doi.org/10.1039/C6EE01655C

137. B. Seger, A.B. Laursen, P.C.K. Vesborg, T. Pedersen, O. Hansen, S. Dahl, I.B. Chorkendorff, Hydrogen production using a molybdenum sulfide catalyst on a titanium-protected $\mathrm{n}^{+} \mathrm{p}$-silicon photocathode. Angew. Chem. Int. Ed. 51(36), 9128-9131 (2012). https://doi.org/10.1002/anie.201203585

138. S.N. Habisreutinger, T. Leijtens, G.E. Eperon, S.D. Stranks, R.J. Nicholas, H.J. Snaith, Carbon nanotube/polymer composites as a highly stable hole collection layer in perovskite solar cells. Nano Lett. 14(10), 5561-5568 (2014). https://doi. org/10.1021/nl501982b 